\title{
The Dependence of Confidence Processing on Working Memory
}

A thesis submitted to the Faculty of Graduate Studies and

Research in partial fulfillment of the requirements for

the degree of Masters of Arts

by

Jordan Schoenherr

Department of Psychology

Carleton University

Ottawa, Ontario

January 2008

(C) 2008 Jordan Schoenherr 


$\begin{array}{ll}\begin{array}{l}\text { Library and } \\ \text { Archives Canada }\end{array} & \begin{array}{l}\text { Bibliothèque et } \\ \text { Archives Canada }\end{array} \\ \begin{array}{l}\text { Published Heritage } \\ \text { Branch }\end{array} & \begin{array}{l}\text { Direction du } \\ \text { Patrimoine de l'édition }\end{array} \\ \begin{array}{l}\text { 395 Wellington Street } \\ \text { Ottawa ON K1A 0N4 }\end{array} & \begin{array}{l}\text { 395, rue Wellington } \\ \text { Ottawa ON K1A ON4 }\end{array} \\ \text { Canada } & \begin{array}{l}\text { Canada } \\ \end{array}\end{array}$

Yourfile Votre référence

ISBN: 978-0-494-36814-5

Our file Notre référence

ISBN: 978-0-494-36814-5

NOTICE:

The author has granted a nonexclusive license allowing Library and Archives Canada to reproduce, publish, archive, preserve, conserve, communicate to the public by telecommunication or on the Internet, loan, distribute and sell theses worldwide, for commercial or noncommercial purposes, in microform, paper, electronic and/or any other formats.

The author retains copyright ownership and moral rights in this thesis. Neither the thesis nor substantial extracts from it may be printed or otherwise reproduced without the author's permission.
AVIS:

L'auteur a accordé une licence non exclusive permettant à la Bibliothèque et Archives Canada de reproduire, publier, archiver, sauvegarder, conserver, transmettre au public par télécommunication ou par l'Internet, prêter, distribuer et vendre des thèses partout dans le monde, à des fins commerciales ou autres, sur support microforme, papier, électronique et/ou autres formats.

L'auteur conserve la propriété du droit d'auteur et des droits moraux qui protège cette thèse. $\mathrm{Ni}$ la thèse ni des extraits substantiels de celle-ci ne doivent être imprimés ou autrement reproduits sans son autorisation.
In compliance with the Canadian

Privacy Act some supporting forms may have been removed from this thesis.

While these forms may be included in the document page count, their removal does not represent any loss of content from the thesis.
Conformément à la loi canadienne sur la protection de la vie privée, quelques formulaires secondaires ont été enlevés de cette thèse.

Bien que ces formulaires aient inclus dans la pagination, il n'y aura aucun contenu manquant.

\section{Canadä}




\begin{abstract}
This study examines the role of working memory on the processing of subjective confidence. Participants were required to select either the larger or the smaller of two squares, after which they indicated their level of confidence in their response. As a secondary task, participants randomized letters aloud. Such a task is presumed to occupy attentional resources associated with the central executive component of working memory. Three secondary task conditions were compared: no randomization, randomization concurrent with the decision, and randomization concurrent with both the decision and the confidence report. The results indicated that the presence of the secondary task affected whether confidence processing took place either decisionally or postdecisionally. As such, they provided some evidence for both an alterable locus for confidence processing (Baranski \& Petrusic, 1998) and the notion that confidence processing requires the use of attentional resources.
\end{abstract}




\section{Acknowledgements}

With the completion of this paper comes the realization that it belongs to others as much as it does to me. It seems appropriate to take the time here to acknowledge but a few of those who have in some way contributed to its content either directly or indirectly. First and foremost, I am indebted to Dr. Craig Leth-Steesen for his ceaseless efforts, exceptional expertise, and his patience and indulgence of my academic habits. Deserving an equal mention is Dr. William Petrusic whose profound depth of knowledge and whimsical attitude toward psychological research kindled my interest in psychophysics and confidence processing. Similar thanks are also highly deserved by Dr. Jo-Anne Lefevre for her meticulous eye and commonsense attitude toward research, and Dr. Guy Lacroix for his energy, insight and rigour. Special mention should also be made of Dr. Jim Davies for being the external on my defence committee and Dr. Kevin Nunes for thwarting any attempts on my life during the session in his capacity as chairman.

My acknowledgements would not be complete without a mention of my academic accomplices: the soon-to-be-doctors Joel (Love-Hewitt) Lucas, Steve Carroll, Dean Verger and David McGill. Through our healthy competition, collaboration and antics I have come to appreciate academia. Special thanks also belong to my sister, Mia Schoenherr-Bent, and brother-in-law, Stephen Bent, for letting me mooch during much of my academic forays and Shayla Brush for her tolerance, understanding, and love. Finally, although there are many other family members and friends who have supported or indulged me, I would finally like to thank Health Canada for the 'grant money'. 
Table of Contents

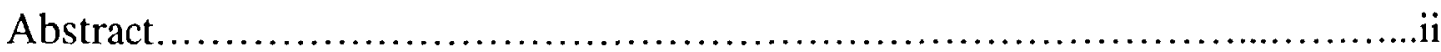

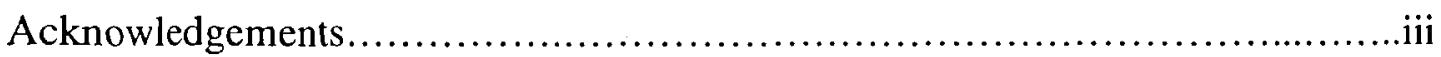

Table of Contents...............................................................

Tables and Figures.........................................................

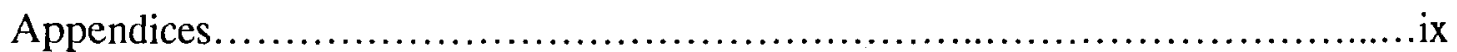

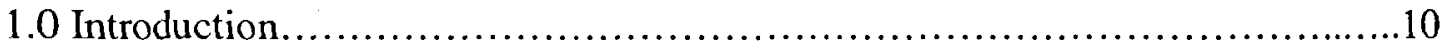

2.0 Models of Confidence Processing.......................................... 11

2.1 A Decisional Locus for Confidence Processing.........................11

2.2 A Postdecisional Locus for Confidence Processing.......................13

2.3 An Alterable Locus for Confidence Processing........................16

3.0 Controlled and Automatic Processing....................................... 18

3.1 The Degree of Automaticity of Confidence Processing...................20

4.0 Working Memory Limitations and Processes...............................21

4.1 Attention and Capacity Limitations..................................23

4.2 The Functions of the Central Executive...............................24

4.3 The Constraints on Executive Control Resulting from Randomization

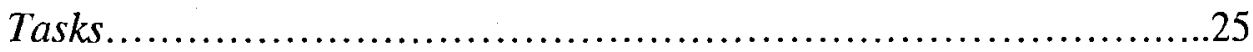

5.0 Present Study...................................................... 27

5.1 Working Memory Secondary Task...............................28

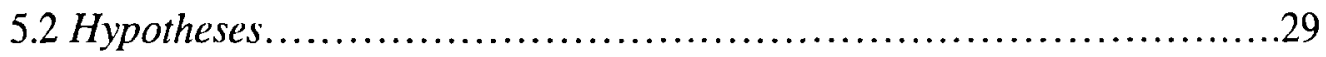




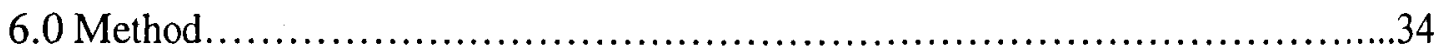

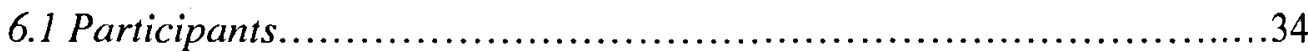

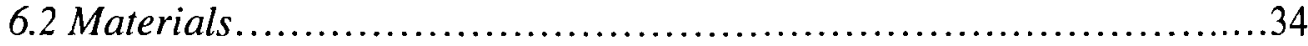

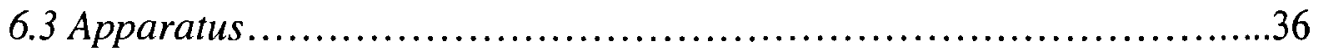

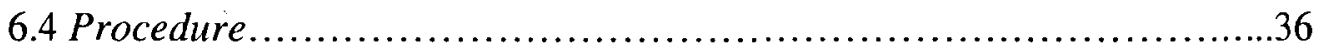

7.0 Results and Discussion........................................................ 41

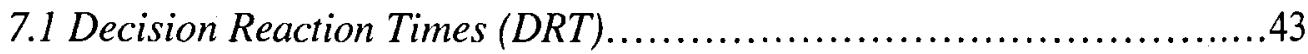

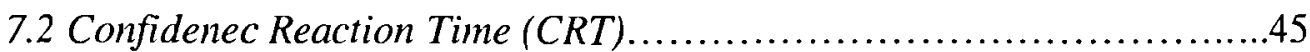

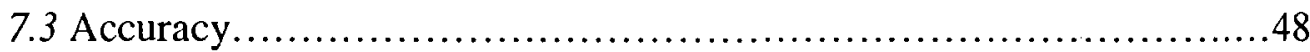

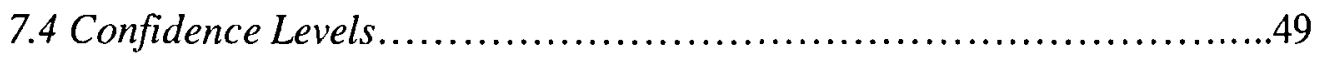

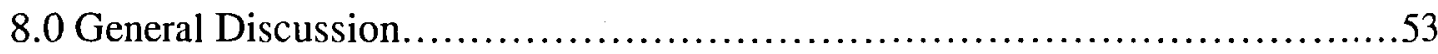

8.1 Implications that the CRT and DRT Results Have For Models of

Confidence Processing ..............................................54

8.2 Accuracy and Confidence Results.....................................56

8.3 Attentional Resources and Confidence Processing.......................58

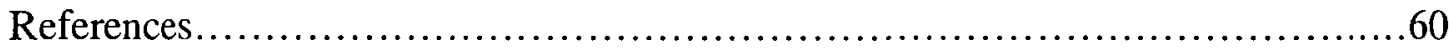

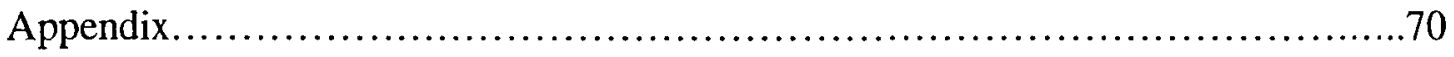

A1.0 Analysis of Randomization Task ....................................... 70

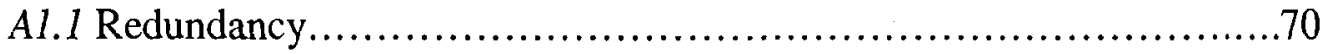

A1.2 Alternations....................................................... 71

A1.3 Adjacency..................................................... 71

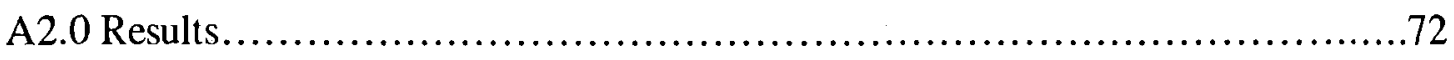

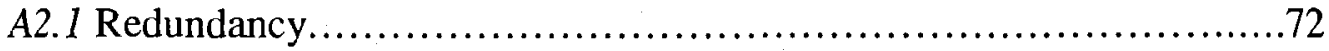


A2.2 Alternations .........................................................

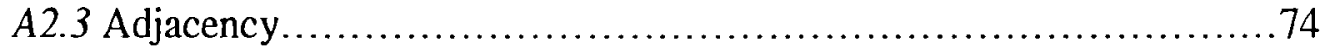

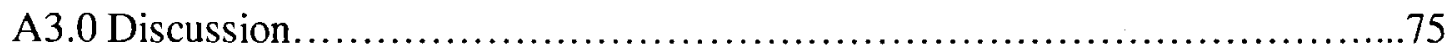


Tables and Figures

Figure 1. Trial event sequences for all load conditions 40

Table 1A. DRTs for Each Working Memory Load Condition Under Both Speed and Accuracy Emphasis.

Table 1B. DRTs for Each Difficulty Level Under Both Speed and Accuracy

Emphasis

Figure 2. Effect of working memory load on confidence reaction time (CRT) across

discrimination difficulty levels for both speed and accuracy stress

Table 2A. Proportion Correct for Each Working Memory Load Condition Under Both Speed and Accuracy Emphasis

Table 2B. Proportion Correct for Each Difficulty Level Under Both Speed and Accuracy

Emphasis

Figure 3. Effect of working memory load on mean confidence across discrimination difficulty levels for both speed and accuracy stress. .52

Figure 4. Comparative effects of working memory load on decision reaction time (DRT) and confidence reaction time (CRT)

Table A1. Percentage Redundancy for Each Working Memory Load Condition Under

Both Speed and Accuracy Emphasis

Table A2. Percentage Alternations for Each Working Memory Load Condition Under

Both Speed and Accuracy Emphasis

Table A3. Percentage Adjacent Pairs for Each Working Memory Load Condition Under 
Both Speed and Accuracy Emphasis........................................... 74 


\section{Appendices}

Appendix: Analysis of Randomization Task.................................... 70 


\subsection{Introduction}

The coordination of attentional, perceptual, and memorial processes is integral to performance in a wide variety of complex cognitive tasks. The concerted operations of these mechanisms are especially necessary for metacognitive judgments (e.g., judgments of ease, feeling of knowing, and subjective confidence) that require a participant to monitor cognitive processes while also generating a decision about their products. From among these metacognitive processes, the study of confidence has enjoyed substantial longevity.

Interest in confidence judgements by psychological researchers can be traced back as early as Henmon (1911) who was the first to demonstrate that decisional response times (DRTs) are inversely related to rated confidence levels. Given the practical importance that judgments of confidence are likely to have on real-life decision making, a large volume of subsequent research has been devoted to measuring the extent to which they are indeed consistent with actual outcomes (i.e., confidence calibration; for reviews see Keren, 1991; Lichtenstein, Fischhoff, \& Phillips, 1982). In a more theoretical vein, there has also been a great deal of interest in the cognitive mechanisms that underlie the production of confidence judgments (Audley, 1960; Baranski \& Petrusic, 1994, 1998, 2001; Busey, Tunnicliff, Loftus, \& Loftus, 2000; Ferrel \& McGoey, 1980; Gigerenzer, Hoffrage, \& Kleinbölting, 1991; Juslin \& Olsson, 1997; Petrusic \& Baranski, 1997, 2003; Vickers, 1979). 
The focus of the current research concerns the nature of the attentional or working memory resource requirements of confidence processing. With respect to such a focus, it is important to note at the outset that this study is the first one to specifically try to address this particular issue. As will be evident, although models of the process of rendering confidence judgments are quite highly specified with respect to both the nature of the mechanisms involved and the type of information used by such processes, they have been silent with respect to their cognitive resource requirements. An examination of this issue within the realm of the judgment of subjective confidence should also begin to shed some light on the resource requirements of metacognitive processes in general.

\subsection{Models of Confidence Processing}

Each of the following models of subjective confidence processing can be distinguished according to two separate, but related, processing aspects. The first aspect is concerned with whether confidence processing occurs concurrently with the primary decision (i.e., has a decisional locus) or commences only after the completion of the primary decision (i.e., has a postdecisional locus). The second aspect involves whether, within a model, confidence arises as a simple by-product of the decision process or as the result of the application of some sort of intervening computational algorithm.

\subsection{A Decisional Locus for Confidence Processing}

Decisional accounts of the locus of confidence processing are founded on the assumption that participants have direct access to the decision process (e.g., James, 1890/1950; Pierce \& Jastrow, 1884) and that confidence reports are a direct reflection of 
the results of that decision process (e.g., Sumner, 1898). One characterization of this view is provided by models of the confidence process developed within the framework of signal detection theory (SDT; Balakrishnan \& Ratcliff, 1996; Ferrel \& McGoey, 1980). For decisions that involve choosing one of two possible alternatives, such models assume that decision making involves the generation of a strength value that represents either the relative (i.e., differenced) perceptual effects of two comparison stimuli or the relative plausibility of two possible semantic response alternatives. Responses are then determined by comparing this strength value to a preset criterion cutoff value and choosing one response if it is above that criterion and the other if it is below (although note that it can also be assumed that responses are made on the basis of the value of the ratio of the likelihood of each response alternative given the strength value).

An important extension of this view that allows for the provision of subjective confidence involves the use of multiple cutoffs to partition the range of possible strength values into intervals representing various degrees of confidence for one or the other of the particular responses, where confidence is assumed to increase the further the interval is from the decision criterion (note that the original impetus for such an extension was that it could be used to obtain receiver operating characteristics; Egan, Schulman, \& Greenberg, 1959). Hence, within such a view, confidence ratings are determined at the same time that the decisions are made within a single process from exactly the same the information.

More recently, with respect to general knowledge decision-making tasks, the 
Running Head: WORKING MEMORY AND CONFIDENCE PROCESSING

probabilistic mental model (PMM) account of confidence processing assumes that the validities of contextually relevant cues generated during the primary decision are direct determinants of the level of confidence (Gigerenzer et al., 1991). This model stipulates that when participants are first engaged in a decision task, they construct a local mental model of that task. This mental model is obtained from readily available traces in memory and is limited to the response alternatives under consideration. If this rapidly activated local mental model leads to a choice response, the participants select the confidence category signifying complete certainty.

Failure of the initial local mental model results in the adoption of a broader, probabilistic mental model. In doing so, a contextualization of the decision task draws upon participant's general probabilistic knowledge of their environment. Instead of readily accessible information pertaining to each of the response alternatives, their complete reference class (of which they are a subset) is accessed in long-term memory. From this reference class, probability cues are generated, in an order that depends on their associated cue validity, and tested to determine whether they can provide a response. If so, the cue validities of those cues are used directly to determine the levels of confidence in those responses. If no cues are generated from the reference class, the participants initiate a guess. Hence, within this view as well, confidence ratings are determined at the same time that the decisions are made within a single process from exactly the same the information.

\subsection{A Postdecisional Locus for Confidence Processing}


Postdecisional accounts of the locus of confidence processing assume that confidence is determined after the completion of the primary decision. Namely, a sequence of multiple processes is assumed to occur starting with the primary decision and ending with the application of an algorithm that is used to generate confidence on the basis of the results of that decisional processing. Within all of these accounts, decisional processing involves the sequential sampling of stimulus information (i.e., evidence). They can all be differentiated, however, with respect to both the manner in which the sampled information is assumed to lead to a response and the manner in which confidence is derived once the decision process has been completed.

The runs model (Audley, 1960) characterizes the primary decision as a randomwalk-like process (c.f., Laming, 1968; Link \& Heath, 1975) of the accrual of evidence for each of the decision alternatives. Within this evidence accrual process, samples of information favouring either one or the other of the alternatives are amassed over time. When the number of successive sample events supporting one of the alternatives (i.e., a run) reaches a predetermined criteria, the associated response is initiated. Confidence is then assumed to be inversely related to the number of times that the sequence of sample events vacillated between favouring each alternative (i.e., the number of runs). A greater level of confidence is thus obtained when fewer runs occur before the response can be made.

Instead of basing decision responses on the sequence of sampled events, Vickers (1970) viewed the primary decision in terms of a race between the accumulation of 
evidence favouring each of the decisional alternatives within the two separate accumulators. As well, within this model, sampled evidence is represented and accumulated as actual magnitude information (i.e., similar to SDT strength values) rather than as discrete counts. Once the accumulated amount of evidence on one of the accumulators reaches a threshold, the associated response is initiated. The difference between the final amount of evidence on the accumulators for the dominant (i.e., the one that is ultimately chosen) and the nondominant responses is used to determine confidence (i.e., the balance of evidence; Vickers, 1979). The greater the difference between the final dominant and nondominant accumulated evidence tallies, the higher the level of confidence.

Finally, the doubt-scaling model of Baranski and Petrusic (1998; Baranski, 1991; Petrusic, 1992; Petrusic \& Baranski, 1997) assumes that stimulus information favouring each response alternative is accumulated in separate accumulators (like Vickers' model, 1979) but in the form of discrete counts (like Audley's model, 1960). However, their model also allows for the sampling and accumulation of nondiagnostic, inconclusive evidence that favours neither response alternative (Petrusic, 1992), whereby if the accumulated amount of inconclusive information reaches a certain criterion, a guess response is initiated. To derive confidence for non-guess responses, the total number of samples acquired that either favour the nondominant response alternative or are inconclusive is scaled into a confidence level. A greater level of confidence is thus obtained when the latter total is smaller. 


\subsection{An Alterable Locus for Confidence Processing}

Although SDT, PMM, and the three sequential-sampling models (SSMs) differ greatly in how they assume confidence is generated, they all subscribe to the view that confidence processing has a fixed locus. In stark contrast to such a view, however, Baranski and Petrusic (1998) have demonstrated that confidence can seemingly be produced either decisionally or postdecisionally depending on the specific demands of the task.

Baranski and Petrusic (1998) provided, within a line-length discrimination paradigm, some novel tests of the viability of the fixed decisional- and postdecisionallocus accounts by examining the time taken to produce confidence reports after the primary decision had finished (i.e., confidence reaction time; CRT). Their first two experiments showed that CRT varied quite systematically as a function of the level of confidence reported with faster CRTs for "Certain" and sometimes also for "Guess" responses than for "Low" or "Moderate" responses. As noted by Baranski and Petrusic (1998), such a finding is completely inconsistent with decisional-locus accounts given that they assume a fairly rapid and direct mapping of decisional information onto confidence ratings. It can, however, be accounted for quite nicely by all postdecisionallocus accounts which assume that confidence ratings must somehow be computed after the fact.

In their third experiment, Baranski and Petrusic (1998) also varied instructional emphasis such that their participants were either required to meet a speeded response 
deadline on half of the blocks of trials or to respond as accurately as possible on the other half. Their results showed that when speed was emphasized, CRTs were substantially longer overall than when accuracy was emphasized. On the basis of this finding, Baranski and Petrusic (1998) concluded that whereas the decisional time pressure induced by the emphasis on speeded responding served to ensure that all confidence processing occurred postdecisionally, the emphasis on accurate responding allowed for the initiation of some confidence processing during the primary decision itself. As these researchers argued, this result then implies that confidence processing has an alterable locus and, hence, that the manner in which confidence is derived in all of the previously discussed models likely needs to be reconsidered.

An important related finding by these researchers is that the provision of confidence reports also seems to fundamentally affect the primary decision process itself (Baranski \& Petrusic, 2001; Petrusic \& Baranski, 2000, 2003). Namely, that whenever confidence reports are required, DRTs drastically increase relative to when confidence reports are not required. Although accuracy differences for decisions made with and without confidence reporting have also sometimes been observed (Petrusic \& Baranski, 2003; Schoenherr et al., 2005, 2006), this phenomenon does not appear to be as robust. As argued by Baranski and Petrusic (2001; Petrusic \& Baranski, 2003), the finding of enhanced DRTs when confidence is required is suggestive of the fact that some active confidence processing must be taking place during the primary decision. As such, this finding is at odds with a fixed decisional-locus view which assumes that confidence is 
passively derived at the same time as the decision from exactly the same information.

Although it is also not consistent with a fixed postdecisional-locus view which assumes that confidence processing must always wait until decisional processing is finished, this finding itself cannot serve to rule out the possibility that some (and maybe even the bulk of) confidence processing can occur postdecisionally.

\subsection{Controlled and Automatic Processing}

A fundamental attribute of all cognitive operations is the extent to which they require effort. For instance, processing simple perceptual stimuli appears to be a relatively effortless process, whereas switching between tasks (e.g., Rogers \& Monsell, 1995) could be regarded as being considerably more effortful. Although the extent to which confidence processing is effortful has not been explicitly addressed by any of the models of confidence, the manner in which such processing is assumed to occur in each model could be regarded as implying quite different attentional resource demands. Defining the nature of controlled and automatic processes will help to establish of the general attentional resource requirements of confidence processing, after which the elements of working memory that are required by such processing can also be investigated.

The importance of the differential effort required by tasks was noted as early as James (1890/1950). Posner and Snyder (1974) later furthered the view of automatic processes as unintentional mechanisms concealed from consciousness, utilizing few if any attentional resources. Expanding on this concept, Schneider and Shiffrin (1977; Shiffrin \& Schneider, 1977) characterized controlled processes as limited in capacity due 
to the demands they make on a limited set of attentional resources.

In contrast to controlled processes, automatic operations result in rapid, effortless, ballistic processing of stimuli once initiated. This characterization implies that controlled and automated processes represent two highly differentiated states. Whereas this absolute partitioning of processing characteristics is useful for delineating differences in the resource requirements of various kinds of cognitive operations at the gross level, it is highly underspecified in terms of both the processes and constituent mechanisms that given rise to automaticity. Moreover, this account also implies that processing only occurs in one of these two modes, and that no intermediate states exist.

An alternative theory was proposed by Norman and Shallice (1986; Shallice, 1982) to account for the presence of resource constraints on cognitive processing. Instead of cognitive operations being driven solely by either controlled or automatic processes, these researchers assumed that both types of processes function in tandem to complete a task. The first component in Norman and Shallice's model is an exogenously driven, contention scheduling system operating with pre-established schemes that produce rapid responses to familiar stimuli and tasks. The second component is a supervisory attentional system (SAS). The SAS is an endogenous, effortful mechanism for the management of interference in automatic responses and is capable of developing novel response regimes. When stimuli are encountered the contention scheduling system is initiated. If the product of these operations requires alteration, the SAS must intervene to effect the appropriate modifications to these processes. Together, these two systems can 
explain the variability in the level of automaticity that can be observed across different processes based on the amount of involvement of the SAS (c.f., Hasher \& Zacks, 1979).

Following on the above descriptions, Logan (1988) conceptualized automatization as the buildup of memory traces that are generated each time a stimulus is encountered and processed. The more frequently that one encounters a stimulus, the greater the volume of information related to it that is stored in memory, and the more expediently that information is retrieved when performing a task that involves it. In this way, automaticity occurs in degrees and is dependent on the outcome of a competition between the application of effortful algorithms and the retrieval of task-relevant memory traces. Controlled algorithmic processes are required when no instances exist within memory. Thus, degrees of automatization are in accordance with the amount of exposure from previous events. Viewed in this way, automaticity is represented as a continuum rather than in terms of the discrete states suggested by Schneider and Shiffrin.

\subsection{The Degree of Automaticity of Confidence Processing}

In general, models of the confidence process assume that confidence is based on the products of the primary decision. Consequently, it can safely be claimed that primary decision information must then either be directly translated into a confidence report (Ferrel \& McGoey, 2000; Gigerenzer et al., 1991) or be retained until it can be more rigorously interrogated and manipulated (e.g., Audley, 1960; Baranski \& Petrusic, 1998; Vickers, 1979). To this end, the various models imply a varying need for controlled processing. 
As is evident from the automaticity literature, the simple distinction of controlled and automatic processes must be further qualified. As Norman and Shallice (1986) and Logan (1988) note, all processing involves both kinds of mechanisms to different extents. Consequently, it is important to go further in order to understand what kinds of cognitive architectures might underlie the operations assumed by these models. Instead of a unitary process, a system for carrying out confidence processing should instead be considered.

The most likely system to retain and manipulate the information used by the confidence process is working memory (Baddeley \& Hitch, 1974). In its traditional formulation, working memory is a short-term limited capacity store that maintains information until it is required or decays. However, simply invoking the construct of working memory is an untenable strategy as there are numerous models of working memory that vary with respect to the processes that are assumed to be involved and the storage limitations that are placed upon them.

\subsection{Working Memory Limitations and Processes}

Although the concept of working memory has become entrenched in cognitive psychology, there is little consensus on its general characteristics. The manner in which this limited-capacity store has been characterized, accentuates either the use of specialized buffers (e.g., Baddeley \& Hitch, 1974; Repovs \& Baddeley, 2006) or the level of activation that long-term memory items have in the context of a task (e.g., Anderson, 1983; Conway \& Engle, 1994; Cowan, 1995).

The disparities between these different accounts of working memory were initially 
viewed as irreconcilable as they postulated varied mechanisms for its functioning.

However, Miyake and Shah (1999) have identified several commonalities shared by these theories. An essential recognition of these models is that working memory is not an autonomous mechanism. Rather than a specific cognitive or anatomical structure that retains information, working memory is generally characterized either as a set of functions, processes, or mechanisms from a functionalist view or as long-term memory elements that have a specific level of activation. These functions encompass both domain-specific and domain-general subsystems or activation codes. The domain-specific components of working memory are involved in retention of visual, spatial, and phonological information in a less active state, whereas the domain-general components perform executive functions by actively monitoring and manipulating information within the working memory system. Lastly, resource limitations can result from the interaction of these multiple components, placing constraints on the capacity and duration of storage.

Of these general features of working memory, both capacity limitations and central executive functioning are of great importance regarding their potential contributions to confidence processing. If confidence processing is in fact effortful, it should be expected that limiting either the available resources should alter the manner in which a confidence report is produced. Alternatively, capacity limitations are irrelevant if confidence processing simply represents an automatic generation of a participant's level of confidence. Similar expectations follow with respect to central executive functioning. If confidence processing principally uses domain-general resources, then the concurrent 
Running Head: WORKING MEMORY AND CONFIDENCE PROCESSING

performance of a central executive task should impede the generation of a confidence report.

\subsection{Attention and Capacity Limitations}

Early inquiries into storage capacity by Brown (1958), Miller (1956), and Peterson and Peterson (1959) assumed that memory storage was passive, and that items decayed rapidly unless they were reactivated through additional presentations. An increased understanding of the roles of rehearsal and distraction in the process of retention has expanded this general view into a more robust concept of working memory (e.g., Engle, Kane, \& Tuholski, 1999). Memory systems are now conceived of as an integrated architecture involving the interaction of attention, executive function, long-term memory, and short-term stores.

The resource limitations of the attention system are the first constraint placed on the capacity of working memory (Miyake \& Shah, 1999). Studies on the limits of attentional capacity first noted that when participants were required to process two or more stimuli simultaneously in the same modality (e.g., Duncan, 1980) or were required to switch between tasks (e.g., Rogers \& Monsell, 1995) that performance decrements would result. Although the debate over the locus of interference is still unresolved, many studies attribute it to limitations in central-level response selection mechanisms after stimuli have already undergone some initial degree of processing (e.g., Deutsch \& Deutsch, 1963; Duncan, 1980; Norman, 1968). Identifying the quantity of information that can be processed becomes a concern of extreme importance to determine when 
information must be retained elsewhere.

Despite the lack of a firm consensus on the general limitation of attention (e.g., Awh \& Pashler, 2000; Smilek, Eastwood, \& Merikle, 2000), recent studies support a retention capacity of one item within the focus of attention (Cowan, 2001; McElree, 2001). These limitations stem either from the finite amount of resources within the storage components (Baddeley, 1990), the amount of potential attentional activation (Lovett, Reder, \& Lebière, 1999), or a more general limit of controlled attention (Engle et al., 1999). In general, once the storage capacity is exceeded, any additional information must be retained elsewhere.

Supplementary storage capacity is provided by working memory which actively maintains material outside the scope of attention in a more readily accessible state than long-term memory items (Oberauer, 2002). Unlike early estimates of storage capacity (Brown, 1958; Miller, 1956; and Peterson \& Peterson, 1959) research on the storage capacity of working memory suggests that four items can remain active for a brief duration (Cowan, 1995, 1999) and that this can be shown when chunking is inhibited due either to an excess of information or by interfering with stimulus encoding (Cowan, 2001). Moreover, decrements in this capacity have also been shown to occur when items are accessed or manipulated (Cowan, 1988, 1995, 1999).

\subsection{The Functions of the Central Executive}

Importantly, all models of working memory endorse some form of executive control. A widely held notion is that of a distinction between a central executive and 
subordinate processing components (Baddeley, 1986; Baddeley \& Hitch, 1974) that parallels the work of Norman and Shallice (1980; Shallice, 1982). On this view, the central executive is a single component that actively manipulates information.

Alternatively, Cowan (1988) has suggested that two broad mechanisms are involved in focusing attention, one that is equivalent to a central executive whereas the other system utilizes salient features of the stimulus. However, it is also possible to interpret the recent divisions of the visual-spatial sketchpad and the phonological loop into active and passive subcomponents as being functionally equivalent to this distinction (Baddeley, 1983; Della Sala et al., 1999; Logie, 1995).

Whether executive control is organized into a single mechanism or is in fact a disparate set of functions, it appears to perform a dedicated set of tasks. Baddeley (1996) has identified numerous functions performed by the central executive including the focus, division, and switching of attention as well as long-term memory utilization. Similar processes have also been outlined by Miyake et al. (2000) including updating items in memory, inhibition of responses, and task switching. These operations have been determined through a variety of dual-task paradigms which require participants to perform a primary task in addition to a secondary task. Dual-task interference between the two tasks will occur to the extent that they share the same structures or attentional resources.

\subsection{The Constraints on Executive Control Resulting from Randomization Tasks}

A classic technique to examine executive functioning makes use of secondary 
random generation tasks (Baddeley, 1966). In such tasks, participants are given a set of elements, usually letters or numbers, and are asked to generate a sequence that could have occurred by chance alone. To ensure randomness, participants must continually consult previous items held within memory while generating new ones in order to ensure that those choices match their criterion for randomness. Due to the demands that it places on monitoring and maintaining items in working memory, this task has been widely been assumed to require the use of the central executive (e.g., Baddeley, 1986; Baddeley, Emslie, Kolodny, \& Duncan, 1998).

Moreover, varying the number of response alternatives and the rate at which they are output seems to place differential loads on executive functions. For example, Baddeley (1966) found significant differences in randomization performance related to the number of alternative responses participants could select from (i.e., 2, 4, 8, 16, or 26 letters) in both a paced, where participants were required to respond at a given rate, and an unpaced condition, where they could instead respond at will. Additionally, Baddeley (1966) found significant differences between the conditions involving $2-8$ altematives when participant's performance was paced, but not between the 16 and 26 alternative conditions.

It is important to note here, though, that the way in which randomness itself should be appropriately be conceptualized is a highly contentious issue which still remains largely unresolved. For example, one troublesome fact is that any sequential response pattern can always potentially occur by chance, although the probability of it 
doing so may be remote (e.g., 10 "Heads" in a row). To avoid these issues, a definition of randomness cited by Nickerson (2002) is adopted here which characterizes a random sequence as maintaining the equiprobability of alternatives, the sequential independence or unpredictability of events, and the irregularity and incompressibility of random sequences.

Furthermore, research involving the generation of random sequences typically has shown that such performance is subject to various kinds of biases, the most ubiquitous one being a tendency to overalternate between the response alternatives more than would be expected due to chance. One explanation for this tendency is that participants in randomization studies try to ensure that the subsequences within a small memory window of 5 or 6 previous responses are always locally representative of the general characteristics of the random sequence as a whole, the most salient one of which is the equiprobability of the response alternatives. As discussed by Kareev (1992), such local representativeness "in the short term" ensures that too much alternation occurs across the sequence as a whole. Nonetheless, studies that have properly informed participants of the characteristics of a random sequence (Nickerson, 2002) or have given participants feedback about the randomness of their performance (Neuringer, 1986) have been able to enhance randomization performance.

\subsection{Present Study}

From the above review, two views regarding the potential role of working memory resources within the confidence process can be outlined. The first involves a 
confidence process that requires storage but no active manipulation of its content. Such an account emphasizes the automaticity of confidence processing. If confidence reports are generated by an automatic process, a working memory load involving executive control should have little to no significant impact on its functioning. The relevant modal subsystem would passively maintain decisional information until the confidence response is required, at which point that information would be directly scaled into the relevant confidence category.

Alternatively, working memory would be needed in order to actively rehearse or maintain decisional information until it is transmitted to the subsequent confidence process. Moreover, within that process, working memory would also be required to perform the additional mental operations that would culminate in a confidence response. In this case, occupying executive functions with a working memory secondary task should drastically affect confidence processing by interfering with and interrupting its functioning.

\subsection{Working Memory Secondary Task}

The aim of the present experiment is to sufficiently occupy executive function so as to interfere with confidence processing. Hence, a concurrent letter randomization task was used to introduce a load on central executive resources. If confidence processing is effortful, it should make use of similar resources. This secondary task was performed along with a primary perceptual discrimination task either during just the primary decision itself (which was then followed by a confidence response) or during both the 
primary decision and the confidence response phases. Two control conditions were also performed. One in which the participants performed the discrimination task plus a confidence response without the secondary letter randomization task, and another where participants were required to perform the letter randomization task on its own. A condition involving the performance of the secondary load task during only the confidence response phase was not attempted given the inherent difficulty involved in having participants initiate the letter randomization task just as the primary decision is ending but before their confidence response. As a whole, these dual-task manipulations should allow for a determination of whether or not the confidence process requires central executive resources and, if so, whether they are required decisionally or postdecisionally.

\subsection{Hypotheses}

As discussed previously, decisional-locus SDT and PMM accounts collectively assume that confidence and primary decision processes are inseparable. Moreover, given that the evidence base for both the primary decisions and the confidence ratings is assumed to be identical in these models, it could also be expected that only limited invariant resources are required to produce confidence. Namely, such a view would regard primary decisional processing as the major effortful operation, with confidence levels resulting from a relatively effortless mapping of decisional information (i.e., signal strength or cue validity, respectively) onto predetermined confidence categories supplied by the experimenter

The decisional-locus account would lead to several predictions regarding the 
effect of central executive, dual-task interference. First, the presence of such interference during the primary decision should likely serve to both slow DRTs and decrease decisional accuracy by interfering with decisional processing (and note that this prediction will be relevant for the following accounts as well). Second, if confidence is automatically generated along with the primary decision, the presence of dual-task interference during the decision should influence confidence processing (i.e., confidence levels) only indirectly by making the primary decision task uniformly more difficult than it would be without dual-task interference. Third, such a view would also predict that if the dual-task interference is extended so that it also occurs after the primary decision, the additional associated costs for confidence processing (with respect to both confidence levels and CRTs) should be minimal because no additional resources would need to be devoted postdecisionally to such processing. However, it could be expected that such interference would serve to invoke an overall delay in the participant's actual confidence responses. Finally, note that these predictions would not be expected to change under instructions emphasizing speeded responding, because although such a manipulation would almost certainly affect the manner in which decisional processing occurs, decisional-locus accounts would still assume that confidence itself is simply read-off of the results of that decisional processing.

Postdecisional-locus SSM accounts, on the other hand, assume an inherent separability between confidence and primary decisional processes in that confidence is always determined after the decision has been made. Moreover, according to all of these 
accounts confidence must be computed on the basis of a retrospective interrogation of the results of the evidence accrual decision process (e.g., Vickers', 1979, balance of evidence). Under this view, it could be expected that some amount of attentional or working memory resources would be required by the confidence process in order to both maintain those evidence accrual results and apply the algorithm used to compute confidence to them.

Hence, the postdecisional-locus account would also lead to several predictions regarding the effect of central executive, dual-task interference on confidence processing. Namely, given that confidence processing is assumed to occur only postdecisionally, the presence of dual-task interference during the primary decision should influence confidence processing (i.e., confidence levels) only indirectly by making the primary decision task uniformly more difficult than it would be without dual-task interference. However, in contrast to the decisional-locus account, a postdecisional-locus account would predict that if the dual-task interference is extended so that it also occurs after the primary decision, then confidence processing should be affected quite dramatically resulting in much slower CRTs. Finally, note that these predictions would not be expected to change under instructions emphasizing speeded responding, because although such a manipulation would affect decisional processing, postdecisional-locus accounts assume confidence is always computed after decisional processing is finished.

Alterable-locus-of-confidence accounts also assume an inherent separability between confidence and primary decisional processes in that confidence can be 
determined either during the decision process or after it has finished (or both). With respect to the resource requirements of confidence processing within such an account, the very fact that changing the speed versus accuracy instructional emphasis can seemingly affect whether confidence is determined postdecisionally or decisionally (Baranski \& Petrusic, 1998, 2001) necessarily implies that the production of confidence is a timeconsuming and, hence, effortful process. Moreover, the fact that DRTs have been shown to become slowed whenever confidence reports are required also implies both that confidence processing is occurring during the primary decision and that it is using up some of the cognitive resources required by the decision process (Baranski \& Petrusic, 2001; Petrusic \& Baranski, 2000, 2003; Schoenherr et al., 2005, 2006).

Hence, the alterable-locus account would also lead to several predictions regarding the effect of central executive, dual-task interference on confidence processing. Namely, given that confidence processing can be invoked either decisionally or postdecisionally within such a view, the presence of dual-task interference during the primary decision should serve to have to an affect that is analogous to that which occurs under speed stress, namely, to ensure that all (or at least most) of the confidence processing becomes delayed and takes place postdecisionally. If so, then CRTs would now be expected to be much slower even though dual-task interference is only being applied decisionally (and, as before, confidence levels would also be expected to be influenced by the increased decisional difficulty invoked by the dual-task interference). Next, alterable-locus accounts would predict that if the dual-task interference is further 
extended so that it also occurs after the primary decision, some processing of confidence during the primary decision itself should now reoccur given that the inherent advantage of doing all of the confidence processing postdecisionally is now gone. If so, given the presence of dual-task interference during the confidence reporting period, CRTs would still be expected to be slowed in comparison to those observed when no dual-task interference is present anywhere in the trial, but probably not slowed to the same extent as when dual-task interference occurs only during the primary decision. Interestingly, such a view would also predict that DRTs should be larger when dual-task interference is present during both the primary decision and the confidence response phase in comparison to when it is present solely during the primary decision.

Finally, the alterable-locus view would predict that under instructions emphasizing speeded responding, all confidence processing should then be occurring postdecisionally leading to predictions analogous to those made with respect to the postdecisional-locus view but only when speed is emphasized. Hence, under speed stress, CRTs for trials with no dual-task interference should then be expected to be more comparable to those observed for trials where dual-task interference is present only during the primary decision, but CRTs for trials where dual-task interference is present during both the primary decision and confidence response phase should now be much longer than for the other two conditions. 


\subsection{Method}

\subsection{Participants}

Thirty-four undergraduates participated in a single one-hour session. They were awarded $1 \%$ toward their final grade in Introductory Psychology.

\subsection{Materials}

Discrimination Task. The primary decision consisted of a square-size discrimination task. The stimulus set for this task consisted of four squares with equal vertical and horizontal dimensions of $60,61,62$, or 63 pixels respectively. On each trial, two black squares were presented against a white background, side-by-side in the middle of the computer screen. The $60 \times 60$ square acted as a standard stimulus to which each of the other square stimuli were compared creating three discrimination difficulty levels (easy, intermediate, and hard). For each difficulty level, half of the time the standard square was presented on the left and half of the time it was presented on the right. When the standard was presented on the left, its bottom edge was 2 pixels lower than the bottom edge of the comparison stimulus, but when the standard was presented on the right, its upper edge was 2 pixels higher than the upper edge of the comparison stimulus. In addition, for each of these left-right stimulus presentation orders, the stimuli were also horizontally offset by 40 pixels half of the time and by 44 pixels the other half of the time (both of these the vertical and horizontal positioning differences were invoked as a means help to ensure that the participants could not use the monitor as a cue). As well, the square stimuli were always followed by a pattern mask consisting of two $70 \times 80$ pixel 
oval shapes located where the squares had been presented.

Confidence Report. Confidence rating responses were made on a decade scale from 50 through 100, where 50 indicated that the participant was guessing and 100 indicated complete certainty in the response.

Randomization Task. The secondary task required participants to verbally randomize the letters " $A$ " through " $F$ " at a consistent rate. Six alternatives were chosen in order to place a nontrivial load on executive resources. Verbal randomization responses were used so as to minimize both input interference with the visually presented square stimuli and output interference with the manual responding used for the decision task and confidence report. Moreover, randomization of the letters " $A$ " through " $F$ " appears appropriate in order to avoid confounds that may arise from using digits as randomization stimuli which might then directly interfere with the numeric representations of the confidence-rating categories.

To indicate the onset of the randomization task, a pure tone with a frequency of $500 \mathrm{~Hz}$ and an amplitude of $55 \mathrm{~dB}$ was presented for $250 \mathrm{~ms}$. A second tone was presented (also for $250 \mathrm{~ms}$ ) either after the response to the primary decision or after the confidence report depending on the experimental condition. This second pure tone had a frequency of $990 \mathrm{~Hz}$ and an amplitude of $55 \mathrm{~dB}$ indicating the cessation of randomization task. In addition to these tones, a metronome beat occurred at a rate of $80 \mathrm{bpm}$ during all conditions at a frequency of $700 \mathrm{~Hz}$ and amplitude of $50 \mathrm{~dB}$. This beat was introduced to guide the random letter generation task as will be discussed below. Neither tone was 
presented during the no-randomization control block because evidence suggests that even the presentation of a salient signal alone does not use attentional resources (e.g., Hochman \& Meiran, 2005; Jolicoeur, 1999, Experiment 1).

\subsection{Apparatus}

A Pentium 1 computer using SuperLab experimental software randomly presented the stimuli to the participants on a SVGA monitor. A standard keyboard was used for participants to indicate their decision using either the " $\mathrm{Z}$ " or the " $p$ " keys indicated on the keyboard with a "1" and "2" respectively. If the stimulus on the left corresponded to the correct response the participant pressed the "1". Alternatively, if the stimulus on the right corresponded to the correct response, the participant pressed " 2 ". Levels of confidence were selected using the keys "C", "V", "B", "N", "M", and "," labelled with the respective confidence levels 50 through 100 in increments of 10 .

\subsection{Procedure}

Prior to engaging in an experimental block, participants performed a training block within which they received one trial from each secondary task condition in order to familiarize them with the nature of coordinating the simultaneous performance of the tasks. Corrective feedback on the randomization task was also given here to ensure that the sequences produced by the participants adhered to Nickerson's (2002) definition of randomness that had been given to them by the experimenter.

For the randomization task, participants were instructed to say a letter with each beat of the metronome in order to disallow any self-paced responses strategies. The 
participants were further instructed to avoid alphabetical sequences, repeating letters, or discernable pattern in the letters that they produced (e.g., words or sequences). To ensure a consistent pace that would present some difficulty, TempoPerfect software was used to generate a beat $80 \mathrm{bpm}$ on an Acer Aspire 3610 laptop at which time participants were to respond with a random letter. A separate computer was used in order to ensure that there would be no interference with the recording of the dependent variables by Superlab experimental software. These responses were recorded on 90 min cassettes (one side per participant) or recording software.

Each experimental block consisted of 48 trials. At the beginning of a block of trials, participants were informed as to whether they would be required to randomize letters or not. They were also told whether they would first be required to select either the larger or the smaller of the two stimuli. Halfway through the block, the "Larger" or "Smaller" instruction was switched. The randomization-offset tone cue was used to ensure that participants did not forget when to stop performing the letter randomization task. As mentioned, on the blocks of trials where no letter randomization was required, no onset or offset cues were used.

Figure 1 graphically displays the sequence of events for all three load conditions. In general, trial initiation was left to the discretion of the participant by pressing the space bar at a "READY" screen. In the no-load condition, the square stimuli were presented immediately afterwards for $250 \mathrm{~ms}$ followed by the pattern mask for another $50 \mathrm{~ms}$. They were followed by the instructional response cue indicating whether to select the 
"LARGER?" or "SMALLER?" of the squares. After the response, the word

"CONFIDENCE" appeared which cued them to provide a confidence report. After 500 $\mathrm{ms}$, the next trial was initiated.

Immediately after pressing the space bar in the two randomization conditions (i.e., the decision-load and the full-load conditions), a randomization onset cue sounded for $250 \mathrm{~ms}$ indicating to the participant to start randomizing the letters. After $5 \mathrm{~s}$, participants were presented with the square stimuli for $250 \mathrm{~ms}$, the pattern mask for $50 \mathrm{~ms}$, and the instructional response cue while continuing to simultaneously perform the random letter generation task. On those blocks where the participant was required to stop randomizing letters after the primary decision had been made (i.e., the decision-load condition), the offset tone would sound for $250 \mathrm{~ms}$ which was then followed by the confidence cue. Alternatively, when participants were required to stop randomizing after confidence (i.e., the full-load condition), the offset tone sounded after the confidence report. During all trials, the metronome rate remained constant at $80 \mathrm{bpm}$ to pace the randomization task and to remove it as a confound. The order in which the three working memory load blocks were performed was counterbalanced across participants. As well, a final block of trials was completed at the end of the experimental session for which participants were only required to generate random letter sequences and not to respond to the discrimination task.

Finally, participants were also placed in either a speed- or accuracy-stress condition. Under accuracy stress $(n=18)$, participants were simply instructed to respond 
Running Head: WORKING MEMORY AND CONFIDENCE PROCESSING

as accurately as possible. In contrast, the speeded condition $(n=16)$ required participants to respond within $500 \mathrm{~ms}$ of the offset of stimulus and pattern mask presentation. On those occasions when participants did not meet this deadline, the message "Too Slow" appeared on the screen after the primary decision for $250 \mathrm{~ms}$. In the decision-load condition, this feedback message was followed by the randomization offset tone. 


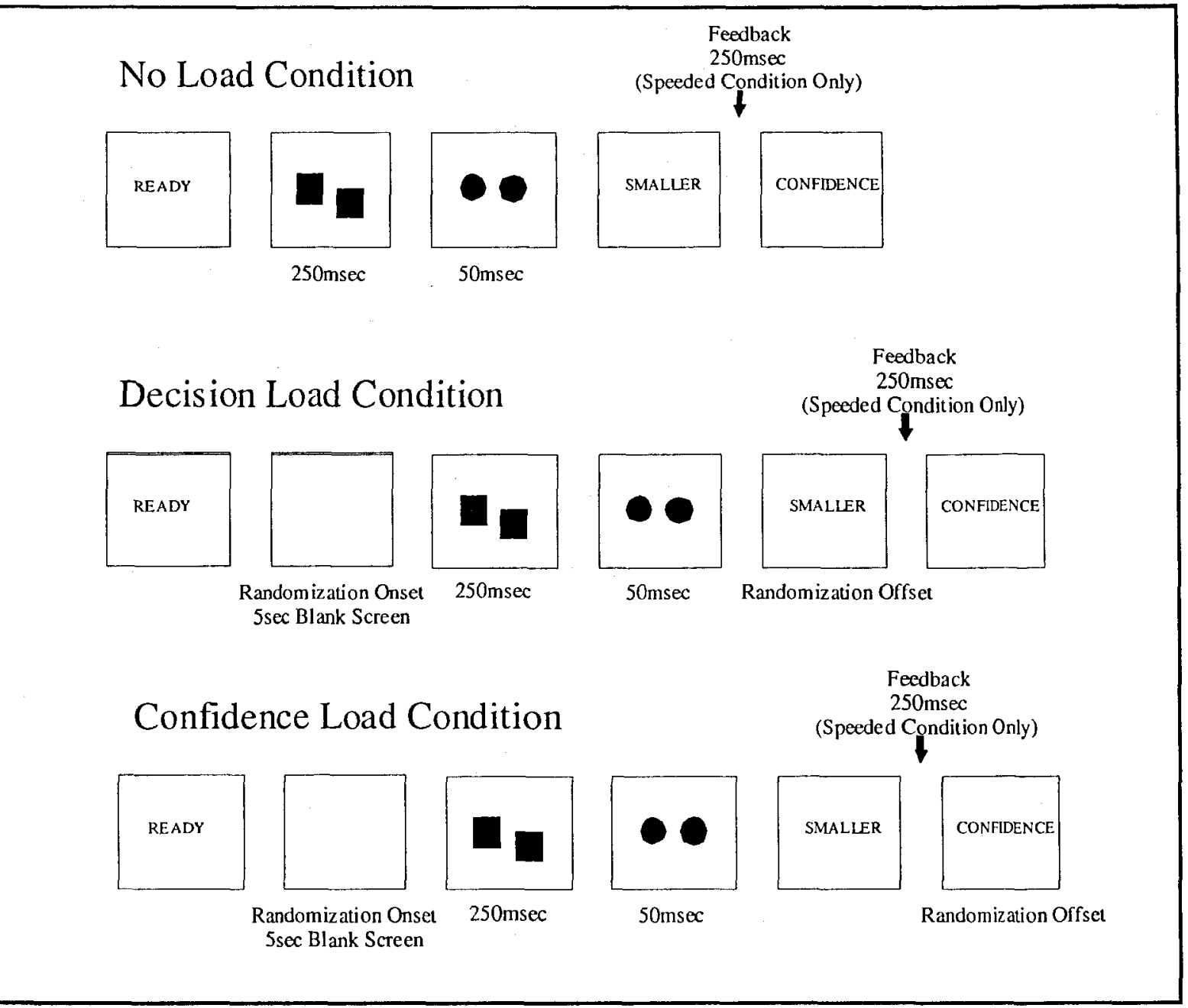

Figure 1. Trial event sequences for all load conditions. The no-load condition required participants to select the appropriate square in accordance with the instruction, followed by the selection of a confidence level. The decision-load condition required participants to begin randomizing letters for $5 \mathrm{~s}$ prior to stimulus presentation. A tone cued cue them to stop after they had selected their primary response. The full-load condition was similar with the exception that the cue to stop randomization occurred after the confidence report has been rendered. 


\subsection{Results and Discussion}

The relevant dependent measures were DRTs (measured from the onset of the instructional response cue), CRTs (measured from the onset of the confidence cue), accuracy (arcsine transformed), and confidence levels. They were all analyzed in separate $3 \times 3 \times 2$ ANOVAs which included the three difficulty levels (easy, intermediate, and hard discriminations) and the three working memory load conditions (no load, decision load, and full load) as within-subject factors and instructional emphasis (speed and accuracy stress) as a between-subject factor. All posthoc analyses were performed using the Bonferroni pairwise comparison procedure. In addition, three performance measures of the randomness of the letter randomization sequences provided by the participants were also obtained and analysed, the results of which are provided in the Appendix.

The four dependent measures were obtained after averaging over both the two "Larger" and "Smaller" instructions, the two left-right presentation orders of the standard and comparison stimuli (with the accompanying vertical offsets), the two horizontal offsets, and two replications of each of those stimulus conditions per difficulty level in each block of 48 trials per working memory load condition. To account for the presence of the randomization offset tone cue in the decision-load blocks, $250 \mathrm{~ms}$ was added to all of the CRTs in those blocks. To account for the presence of the feedback message which sometimes intervened between the decision and confidence responses for the participants in the speed-stress condition, $250 \mathrm{~ms}$ was also added to the CRT data whenever the "Too 
Slow" message occurred. To reduce the influence of slow response time outliers, DRTs and CRTs that were more than 3 SDs above a participant's mean for the corresponding block of 48 trials in each working memory load condition were then removed. These stipulations resulted in $1.78 \%$ and $1.59 \%$ of the total DRT and CRT data being excluded from the analyses, respectively.

Due to a limitation in the experimental software, as mentioned, trial-by-trial feedback for the speeded condition could only occur following the primary decision but prior to the confidence report. This represented a potential confound that must be examined prior to any further analysis. A paired samples $t$-test that was performed on mean confidence scores for participants in the speed-stress condition revealed that on trials where participants received feedback indicating that they were "Too Slow", they were less confident $(M=76.3)$ than for trials where they did not receive such feedback $(M=80.3), t(16)=2.13, p=.049$. However, the overall within-participant levels of confidence when feedback was received and not received, were highly correlated $r^{2}(16)=$ $.729, p<.005$. Univariate ANOVAs performed on each participant's confidence responses identified 6 participants that were affected out of the 17 within the speeded condition (35\% of the sample). Thus, these effects appear to be due to individual differences and, hence, may not present a critical problem for the results. An individual difference account of these effects was supported by a preliminary analysis that included those participants who exhibited feedback-affected performance as a between-subjects variable. This ANOVA demonstrated that the between-subjects variable of feedback 
effects were not significant on its own, $F(1,31)=.774, p=.386$, nor did it interact with any of the other factors (i.e., working memory load, difficulty level, and speed-accuracy stress). As a consequence, this between-participants feedback factor was not included in any further analyses.

\subsection{Decision Reaction Time (DRT)}

In the ANOVA with DRT as the dependent measure, primary decision response latencies were found to vary significantly with working memory load, $F(2,64)=3.939, p$ $<.05, M S E=141916$ (see Table $1 \mathrm{~A}$ ). Posthoc analyses revealed only that the no-load and full-load conditions significantly differed from one another $(p<.01)$. As the means in Table $1 \mathrm{~A}$ indicates, when a working memory load was placed on both the decisional and the confidence reporting phases, the increase in DRT far exceeded the increase that was evident when a load was placed on the primary decision alone. As the decisional process is necessarily completed before any additional load on the confidence phase is enacted, this result seems to indicate that some confidence processing could indeed have been occurring during the primary decision in the full-load condition that was not occurring in the decision-load condition. 
Running Head: WORKING MEMORY AND CONFIDENCE PROCESSING

Table 1A. DRTs for Each Working Memory Load Condition Under Both Speed and Accuracy Emphasis.

No Load Decision Load Full Load_ Mean

$\begin{array}{lllll}\text { Accuracy } & 970 & 1097 & 1202 & 1090 \\ \text { Speed } & 386 & 301 & 429 & 372 \\ \text { Mean } & 678 & 699 & 816 & 731\end{array}$

Table 1B. DRTs for Each Difficulty Level Under Both Speed and Accuracy Emphasis.

Hard Intermediate Easy Mean

$\begin{array}{lllll}\text { Accuracy } & 1133 & 1083 & 1053 & 1090 \\ \text { Speed } & 386 & 374 & 356 & 372 \\ \text { Mean } & 760 & 729 & 704 & 731\end{array}$

Difficulty level also significantly affected DRT, $F(2,64)=5.948, p<.005, M S E$ $=13187$ (see Table 1B). Posthoc analyses revealed a significant difference between only the hardest and the easiest difficulty conditions $(p<.01)$. The means in Table $1 \mathrm{~B}$ indicate that DRT decreased as the discriminations got easier. Finally, the main effect of the speed versus accuracy stress proved to be significant, $F(1,32)=73.319, p<.001, M S E=$ 535290. As was certainly expected, DRTs were much higher in the accuracy-stress than in the speed-stress condition. 


\subsection{Confidence Reaction Time (CRT)}

The only significant main effect for CRT was that of working memory load, $F(2$, $64)=25.833, p<.001, M S E=304385$. CRT means were 969,1513 , and 1144 in the noload, decision-load, and full-load conditions, respectively. Post hoc analyses revealed that CRT differences were significant between the no-load and decision-load conditions $(p<$ $.01)$ and also between the full-load and decision-load conditions $(p<.01)$. This pattern of results suggests that participants did require more time to compute confidence after the fact in the randomization conditions, but mainly when the working memory load was isolated on the primary decision. As such, both these CRT results and the previous DRT results are consistent with the predictions made by the alterable-locus-of-confidence view. Namely, that placing a working memory load on the primary decision process would serve to induce a full postdecisional shift of confidence processing thus increasing CRTs in the decision-load condition, whereas extending the load to the confidence reporting phase would still encourage participants to do some confidence processing during the primary decision thus increasing both DRTs (given the additional presence of decisional dual-task interference) and CRTs (but not to the same extent as for expected for the decision-load condition). Thus, participants seemed to have been able to optimally shift the locus of their confidence processing depending on the availability of attentional-based, working memory resources.

This pattern of results is somewhat further qualified by the presence of both a 
marginally significant two-way interaction of working memory load and difficulty level, $F(4,128)=2.318, p<.10, M S E=21861$ (see Figure 2), and a three-way interaction of working memory load, difficulty level, and speed-accuracy stress, $F(4,128)=2.334, p<$ $.10, M S E=21861$ (see also Figure 2). With respect to the latter three-way interaction, CRT did not seem differ much between the speed and accuracy stress conditions regardless of difficulty level whenever the working memory load was either absent or placed on both the primary decision and confidence reporting phases. In general, this finding is not consistent with what would have been expected (especially for the no-load condition) under the view that speed emphasis serves induce a postdecisional shift in confidence processing. However, perhaps it is the case that such a shift is less likely to be invoked under speed emphasis when speed versus accuracy instructional emphasis has been manipulated between-participants. Alternatively, the presence of a working memory load during the primary decision on two out of the three blocks in this experiment could have encouraged the participants in the accuracy emphasis condition to do a lot of their confidence processing postdecisionally even when no working memory load was present.

When the load was placed solely on the primary decision, however, CRT was now actually lower under speed than under accuracy emphasis for both the hardest and intermediate difficulty levels. What this effect seems to suggest is that perhaps it is the case that the presence of a speed emphasis on the primary decision invokes a general speed set that then permeates through to the confidence reporting phase resulting in a corresponding speed-up of the CRTs under speed-stress. 


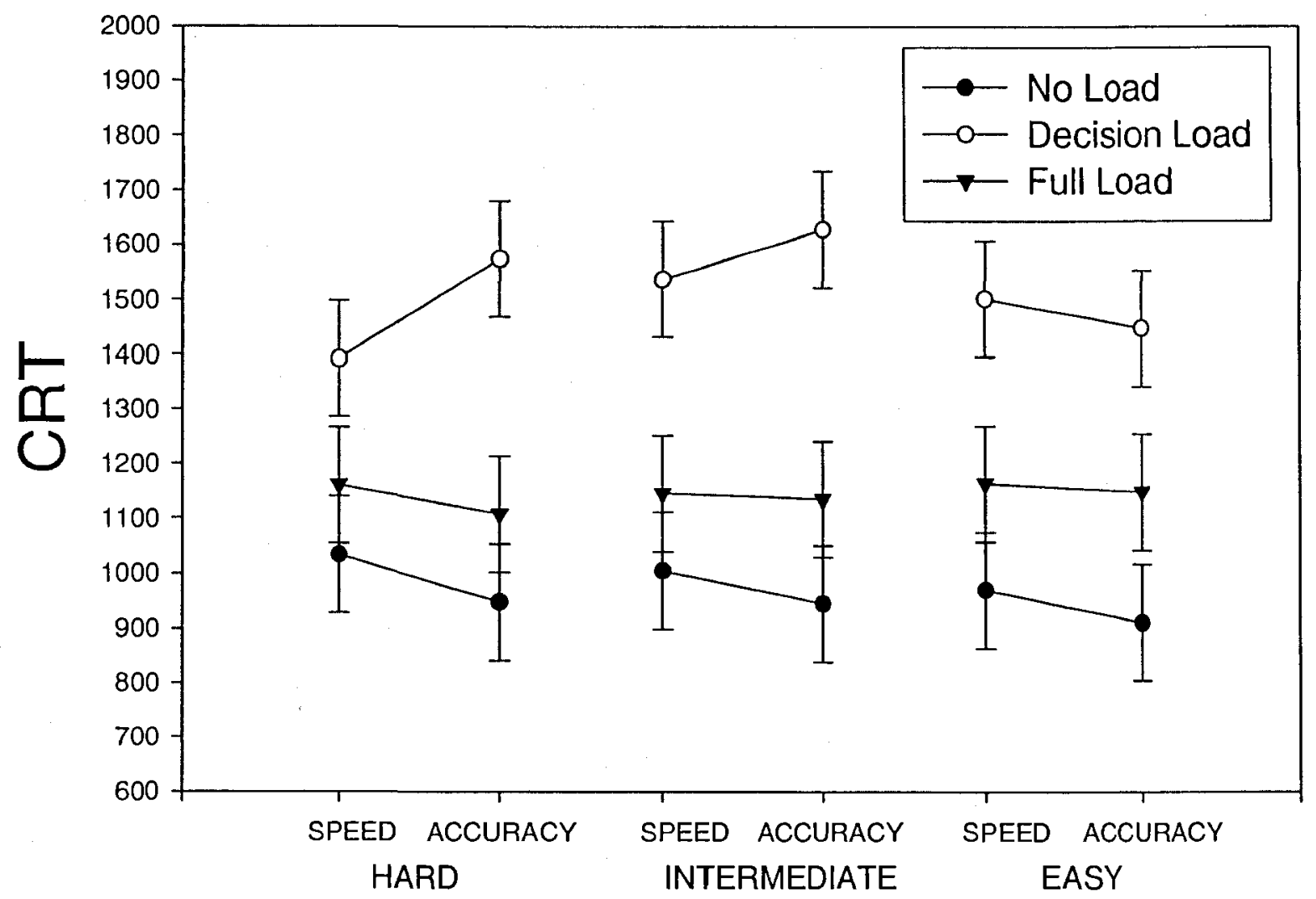

Figure 2. Effect of working memory load on confidence reaction time (CRT) across discrimination difficulty levels for both speed and accuracy stress. Error bars represent half of a Bonferroni confidence interval (C.I.) for the difference between two cell means computed after pooling all of the within- and between-participant factor error terms (nonoverlapping bars indicate that the Bonferroni C.I. around the difference between the cell means would not cover 0 ). 
7.3 Accuracy

In the ANOVA with accuracy as the dependent measure, arcsine transformed proportion correct was found to vary significantly with working memory load, $F(2,64)=$ $8.672, p<.001, M S E=.086$ (see Table $2 \mathrm{~A}$ for mean nontransformed accuracy). Posthoc analyses revealed only that the no-load and decision-load conditions significantly differed from one another $(p<.01)$. Thus, the presence of a working memory load on the primary decision had a greater effect with respect to decreasing accuracy when it did not extend into the confidence reporting phase.

Table 2A. Proportions Correct for Each Working Memory Load Condition Under Both Speed and Accuracy Emphasis.

$\underline{\text { No Load Decision Load Full Load Mean }}$

$\begin{array}{lllll}\text { Accuracy } & .759 & .632 & .692 & .694 \\ \text { Speed } & .708 & .627 & .643 & .659 \\ \text { Mean } & .734 & .630 & .667 & .677\end{array}$

Table 2B. Proportions Correct for Each Difficulty Level Under Both Speed and Accuracy Emphasis.

$\begin{array}{lcccc} & \text { Hard } & \text { Intermediate } & \text { Easy } & \text { Mean } \\ \text { Accuracy } & .598 & .722 & .762 & .694 \\ \text { Speed } & .592 & .662 & .724 & .659 \\ \text { Mean } & .595 & .692 & .743 & .677\end{array}$


Running Head: WORKING MEMORY AND CONFIDENCE PROCESSING

Accuracy also varied significantly with discrimination difficulty level, $F(2,44)=$ $45.399, p<.001, M S E=.035$ (see Table 2B for the mean nontransformed accuracy measures). Posthoc analyses revealed significant differences between all three difficulty levels, the hardest and intermediate conditions $(p=.01)$, the hardest and the easiest conditions $(p=.01)$, and the intermediate and easiest conditions $(p=.01)$. These findings are consistent with expected monotonic decreases in accuracy with increases in the difficulty of the size discriminations. Surprisingly, the main effect of the speed versus accuracy stress proved not to be significant for accuracy itself, $F(1,32)=1.913, M S E=$ $.202, p>.10$, although accuracy was higher in the accuracy-stress than in the speed-stress condition.

\subsection{Confidence Levels}

As for DRT, CRT, and accuracy, working memory load proved to have a significant main effect on confidence levels, $F(2,64)=9.026, p<.005, M S E=75.268$. Mean confidence was $83.4,79.8$, and 79.2 in the no-load, decision-load, and full-load conditions, respectively. Post hoc analyses revealed that confidence level differences were significant between the no-load and decision-load conditions $(p<.01)$ and also between the no-load and full-load conditions $(p<.01)$. These results indicate that participants were indeed aware that the imposition of the working memory loads degrades accuracy. Interestingly, however, the fact that mean confidence was reduced to about the same extent whether the load was placed solely on the primary decision or on both the primary decision and the confidence reporting phase indicates that confidence levels did 
not seem to be tracking the larger reductions in accuracy present in the decision-load condition in comparison to the full-load condition. (One other aspect of these confidence results to note is the fact that they tend to overestimate the actual accuracy measures. In general, though, such overconfidence is a commonly observed phenomena in both semantic and perceptual decision-making paradigms involving fairly difficult discriminations [Baranski \& Petrusic, 1994; Keren, 1991; Lichtenstein et al. 1982], and its presence will not specifically be addressed here.)

Difficulty level again also proved to be significant for confidence levels, $F(2,64)$ $=25.073, p<.001, M S E=22.666$, with post hoc analyses indicating that significant differences occurred between the hardest and intermediate conditions $(p<.01)$, between the hardest and easiest conditions $(p .<.01)$, and between the intermediate and easiest condition $(p<.01)$. Mean confidence was 78,81 , and 83 in the hard, intermediate, and easy difficulty conditions, respectively. Thus, there was a monotonic increase in subjective confidence with a concomitant decrease in difficulty demonstrating that participants were indeed aware of the differences in the difficulty of the decisions imposed by the differences in stimulus size.

Unlike the ANOVA results for accuracy, confidence across difficulty level proved to be differentially affected by load conditions as indicated by the significance of the twoway interaction of working memory load and difficulty level, $F(4,128)=4.493, p<.01$, $M S E=12.625$ (see Figure 3). Moreover, although the main effect of speed versus accuracy was not significant, $F(1,32)=0.001, p>.90, M S E=878.703$ (in fact, mean 
confidence was 80.39 and 80.50 for the accuracy and speed conditions, respectively), the three-way interaction of working memory load, difficulty level, and speed-accuracy stress was significant for confidence levels, $F(4,128)=4.292, p<.01, M S E=12.265$ (see also Figure 3). With respect to the latter three-way interaction, under accuracy emphasis, the relative confidence levels for each of the three working memory conditions tended to mirror the corresponding relative accuracy differences (i.e., decreasing accuracy across the no-load, the full-load, and the decision-load conditions, respectively). Under speed emphasis, however, such a pattern was not as consistently evident even to the extent that mean confidence for the hardest discriminations turned out to be much lower in the fullload than in the decision-load condition. Hence, in this situation, extending the working memory load into the confidence reporting phase did indeed affect the actual levels of reported confidence themselves. This finding suggests that the concurrent performance of the randomization task could have made it harder to maintain the results of the decision process for difficult decisions made under speed stress, thus making it more likely for participants to report that they were guessing. 


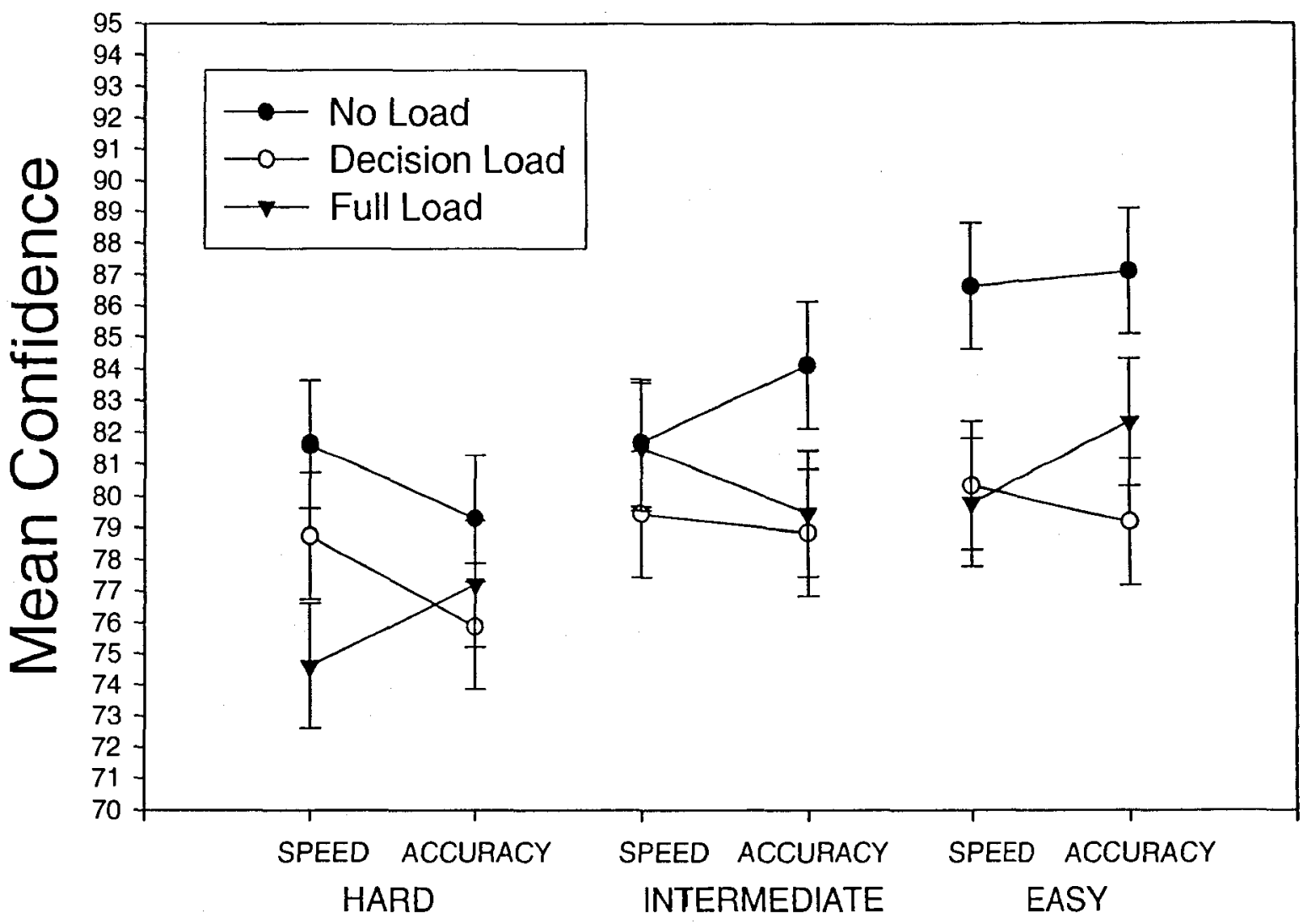

Figure 3. Effect of working memory load on mean confidence across discrimination difficulty levels for both speed and accuracy stress. Error bars represent half of a Bonferroni confidence interval (C.I.) for the difference between two cell means computed after pooling all of the within- and between-participant factor error terms (nonoverlapping bars indicate that the Bonferroni C.I. around the difference between the cell means would not cover 0 ). 


\subsection{General Discussion}

In the present study, a letter randomization secondary task was used to place a load on central executive working memory resources either during the primary decision (i.e., the decision-load condition) or during both the primary decision and the confidence reporting phase (i.e., the full-load condition) of a perceptual discrimination task. The results obtained were as follows: (a) DRTs were much longer in the full-load condition in comparison to the decision- and no-load conditions; (b) CRTs were longer in both the decision- and full-load conditions in comparison to the no-load condition but much more so for the decision-load than for the full-load condition; (c) Accuracy was lower in both the decision- and full-load conditions in comparison to the no-load condition but much more so for the decision-load than for the full-load condition; (d) Confidence levels were lower in both the decision- and full-load conditions in comparison to the no-load condition; (e) Although DRT was much longer when accuracy was emphasized than when speed was emphasized, the speed versus accuracy emphasis instructional manipulation did not have much (if any) of an effect on either CRTs, accuracy, or confidence levels.; and, (f) Finally, no significant interactions involving the speed versus accuracy emphasis instructional manipulation were present for either DRT, CRT, or accuracy although the effect of working memory load on confidence levels was further qualified by a significant three-way interaction with both speed versus accuracy stress and discrimination difficulty level. 


\subsection{Implications that the CRT and DRT Results Have for the Models of Confidence}

Processing

The present CRT and DRT results have specific implications for the various models of the confidence process. First, they were not consistent with the decisionallocus SDT and PMM models that assume a single process for both decisional and confidence processing (e.g., Ferrel \& McGoey, 1980; Gigerenzer et al., 1991). Namely, given that these models assume that confidence is determined directly at the time of the decision, they simply cannot provide any account for the large observed increases in the CRTs in the decision- and full-load conditions.

Second, SSMs that assume that confidence is always determined postdecisionally (e.g., Audley, 1960; Vickers, 1979) are similarly deficient in accommodating these findings. Namely, because it is already assumed in these models that all confidence processing is occurring after the decision, increases in CRTs would only have been expected to occur when the load has been extended into the confidence reporting phase (i.e., for the full-load condition only).

Third, the results involving working memory load are, however, consistent with what was expected according to the alterable-locus-of-confidence view espoused by Baranski and Petrusic (1998, 2001; Petrusic \& Baranski, 2000, 2003). Namely, that placing a working memory load on just the decision process (as in the decision-load condition) would serve to induce a postdecisional shift of confidence processing, thereby dramatically increasing CRTs, but that further extending the load into the confidence 
reporting phase (as in the full-load condition) would induce only a partial postdecisional shift of confidence processing thereby increasing both DRTs and CRTs (but to a lesser extent for the latter measure than the increase expected in the decision-load condition). All of these results were borne out in these data (see Figure 4).

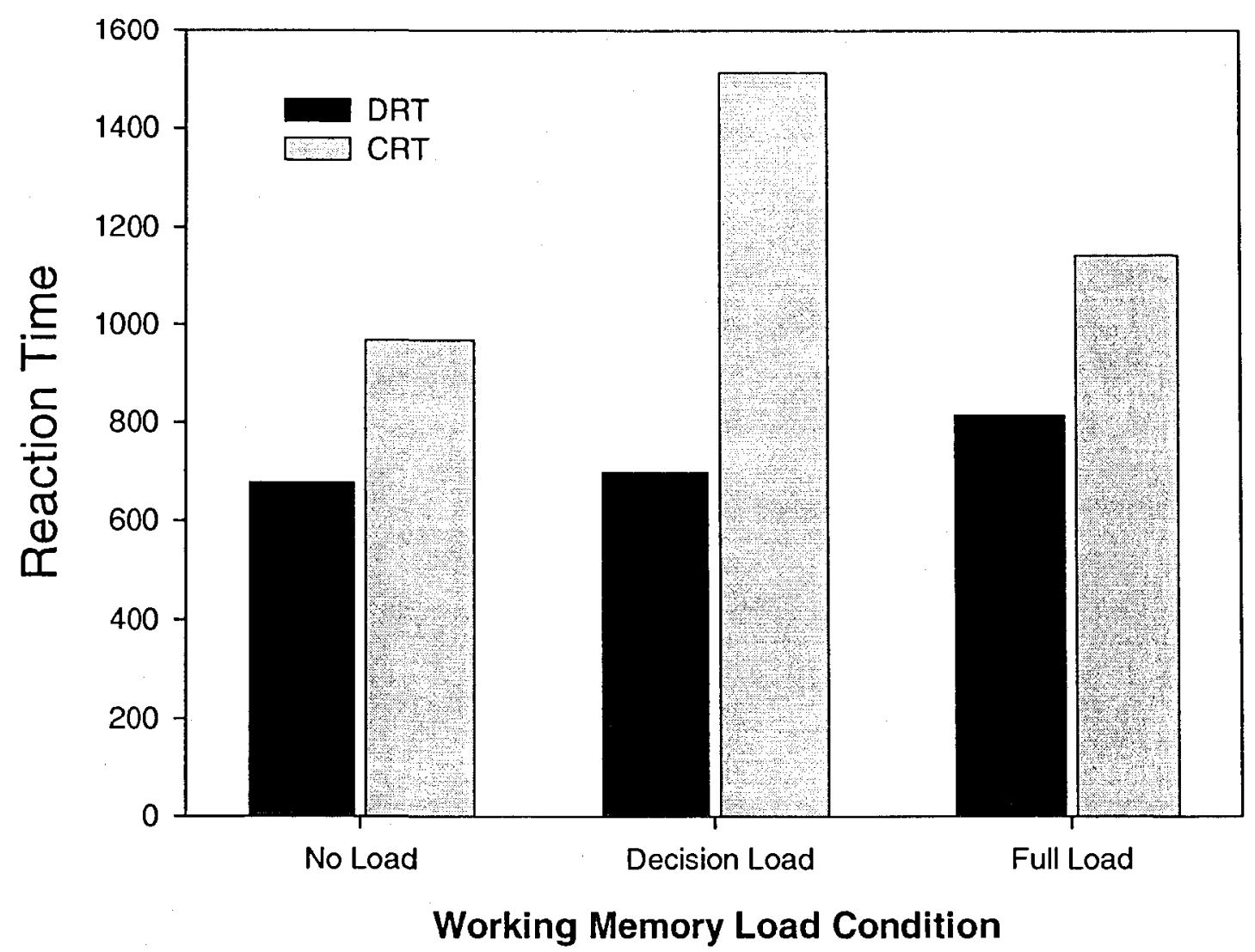

Figure 4. Comparative effects of working memory load on decision reaction time (DRT) and confidence reaction time (CRT). 
Nonetheless, the results obtained here involving the speed versus accuracy emphasis instructional manipulation did not seem to be entirely consistent with the alterable-locus account. In line with Baranski and Petrusic's (1998) findings, it was expected that a postdecisional shift of confidence processing should also have occurred under speed-stress even in the absence of a working memory load. Such a view would then have predicted much longer CRTs in the no-load condition under speed stress than under accuracy stress, which did not specifically occur. However, as indicated previously, it is possible that the presence of a working memory load in the other two load conditions induced at least a partial postdecisional shift of confidence processing in the no-load condition even for participants for whom accuracy was stressed.

\subsection{Accuracy and Confidence Results}

As expected, accuracy was lower when a working memory load was placed on the primary decision (i.e., in the decision- and full-load conditions in comparison to the noload condition). Nonetheless, accuracy was lower still in the decision-load than in the full-load condition which could be regarded as a rather puzzling result given that extending the working memory load after decision should not then be expected to have any further effect on the accuracy of a decision process that has presumably already finished. However, this kind of result might be expected under the view that some confidence processing was occurring during the primary decision in the full-load condition that was not occurring in the decision-load condition (as implied by the corresponding DRT results). Namely, as mentioned earlier (cf., Petrusic \& Baranski, 
2003; Schoenherr et al., 2005, 2006), the presence of confidence processing during the decision processing can sometimes also affect accuracy. As discussed by Schoenherr et al. $(2005,2006)$ increases in accuracy due to confidence processing can occur if such processing serves to either sharpen decisional processing through performance monitoring or induce a state of greater caution.

Confidence levels were also observed to be lower when a working memory load was placed on the primary decision (i.e., in the decision- and full-load conditions in comparison to the no-load condition). Unlike for accuracy though, mean confidence was fairly similar for both the decision-load and full-load conditions indicating that participants were seemingly unaware that responding was somewhat less correct in the former condition than in the latter. Although no explicit predictions involving the effect of working memory load on confidence processing were actually provided earlier, it might have been expected that if such a load interferes with the maintenance of the decisional information such that this information is sometimes being lost before being used by the confidence process, such a state of affairs might then result in lower confidence ratings given that participants would then be more likely to indicate that they were guessing. Under this view, however, such interference should likely have been much greater when the load was extended into the confidence reporting phase than when it was not, lowering confidence ratings accordingly in the full-load condition (although, as mentioned, such a finding did occur but only for the hardest discriminations under speed stress). 


\subsection{Attentional Resources and the Confidence Process}

In general, the fact that the locus of confidence processing can seemingly be altered depending on the presence or not of a central executive, working memory load strongly implies that confidence processing requires domain general, attentional resources. Strictly speaking, the alterable-locus-of-confidence account assumes that the confidence process can be localized to a stage of processing for which time and attentional resources are available for its completion or, similarly, distributed across various stages of processing in a manner that optimizes the available resource use (Baranski \& Petrusic, 1998). In this sense, although the confidence process uses information acquired from the primary decision, it is a separable resource-demanding process. Such a view also implies that confidence processing does not occur in an all-ornone manner, but can adapt to the parameters of the task.

So what exactly are the aspects of the confidence process that require attentional resources? First, confidence processing must certainly involve some form of maintenance and manipulation of the results of the decision process in order to derive a confidence report, processes that are likely to require cognitive resources. Second, the production of a confidence report must involve some form of response selection process in order to map the results of the confidence processing onto an actual confidence response. Response selection has been shown to require central executive resources (e.g., McCann \& Johnston, 1992; Szmalec, Vandierendonck, \& Kemps, 2005).

All of these processes though are ones that necessarily must occur 
postdecisionally. As both this and some previous studies (Petrusic \& Baranski, 1999, $2000,2001,2003)$ have demonstrated there are some aspects of the confidence process that can indeed occur in tandem with the decision process itself. As noted by Baranski and Petrusic (1998) it seems likely that in fact "confidence evolves over the course of the decision process" (p. 942). For example, perhaps the confidence process cannot directly use the results of the decision process but must somehow reformat that information in order to compute confidence. Such a view implies that confidence processing entails an active monitoring of the decision process akin to that which has been assumed to be involved in active error monitoring (cf. Hochman \& Evitar, 2004).

In summary, the present research is consistent with the view that confidence processing is an active monitoring process that uses the executive function of working memory. Like other effortful cognitive operations, confidence processing demonstrates a significant degree of flexibility. This flexibility requires the use of considerable central executive resources, the availability of which determines the locus of confidence processing. To expand upon these findings, future studies should explore whether confidence processing only requires central executive function and whether other components of working memory are involved in storing this information temporarily. 
Running Head: WORKING MEMORY AND CONFIDENCE PROCESSING

References

Anderson, J. R. (1983). The Architecture of Cognition. Cambridge, MA: Harvard University Press.

Audley, R. J. (1960). A stochastic model for individual choice behaviour. Psychological Review, 67, 1-15.

Awh, E., \& Pashler, H. (2000). Evidence for Split Attentional Foci. Journal of Experimental Psychology: Human Perception and Performance, 26, 834-846.

Baddeley, A. (1966). The capacity for generating information by randomisation, Quarterly Journal of Experimental Psychology, 18, 119-129.

Baddeley, A. D. (1983). Working Memory. Philosophical Transactions of the Royal Society of London, B302, 311-324.

Baddeley, A. D. (1986). Working Memory. Oxford: Oxford University Press.

Baddeley, A.D. (1990). Human Memory: Theory and Practice. Hove: Erlbaum.

Baddeley, A. D. (1996). Exploring the Central Executive. Quarterly Journal of Experimental Psychology, 49A, 5-28.

Baddeley, A.D., Emslie, H., Kolodny, J., \& Duncan, J., (1998). Random generation and the executive control of working memory. Quarterly Journal of Experimental Psychology, 51A, 819-852.

Baddeley, A.D., \& Hitch, G. (1974). Working memory. In G.H. Bower (Ed.), The psychology of learning and motivation: Advances in research and theory (Vol. 8, pp. 47-89). New York: Academic Press. 
Running Head: WORKING MEMORY AND CONFIDENCE PROCESSING

Baranski, J. V. (1991). Theories of confidence calibration and experiments on the time to determine confidence. Unpublished doctoral dissertation, Carleton University, Ottawa, ON.

Baranski, J. V., \& Petrusic, W. M. (1994). The Calibration and resolution of confidence in perceptual judgements. Perception \& Psychophysics, 55, 412-428.

Baranski, J. V., \& Petrusic, W. M. (1998). Probing the locus of confidence judgments: Experiments on the time to determine confidence. Journal of Experimental Psychology: Human Perception and Performance, 24, 929-945.

Baranski, J. V., \& Petrusic, W. M. (2001). Testing the architectures of the decisionconfidence relation. Canadian Journal of Experimental Psychology, 55, 195-206.

Balakrishnan, J. D., \& Ratcliff, R. (1996). Testing models of decision making using confidence ratings in classification. Journal of Experimental Psychology: Human Perception and Performance, 22, 615-633.

Brown, J. (1958). Some tests of the decay theory of immediate memory. Quarterly Journal of Experimental Psychology, 10, 12-21.

Busey, T. A., Tunnicliff, J., Loftus, G. R., \& Loftus, E. (2000). Accounts of the confidence-accuracy relation in recognition memory. Psychonomic Bulletin \& Review, 7, 26-48.

Conway, A. R. A., \& Engle, R. W. (1994). Working memory and retrieval: A resourcedependent inhibition model. Journal of Experimental Psychology: General, 123, 354-373. 
Running Head: WORKING MEMORY AND CONFIDENCE PROCESSING

Cowan, N. (1988). Evolving conceptions of memory storage, selective attention, and their mutual constraints within the human information processing system. Psychological Bulletin, 104, 163-191.

Cowan, N. (1995). Attention and memory: An integrated framework. Oxford, England: Oxford University Press.

Cowan, N. (1999). An embedded-processes model of working memory. In A. Miyake \& P. Shah (Eds.), Models of working memory: Mechanisms of active maintenance and executive control (pp. 62-101). New York: Cambridge University Press.

Cowan, N. (2001). The magical number 4 in short-term memory: A reconsideration of mental storage capacity. Behavioral and Brain Sciences, 24, 87-114.

Della Sala, S., Gray, C., Baddeley, A. D., Allamano, N., \& Wilson, L. (1999). Pattern span: A means of unwelding visuo-spatial memory. Neuropsychologia, 37, 11891199.

Deutsch, J. A., \& Deutsch, D. (1968). Attention: Some theoretical considerations. Psychological Review, 70, 80-90.

Duncan, J. (1980). The locus of interference in the perception of simultaneous stimuli. Psychological Review, 87, 272-300.

Egan, J. P., Schulman, A. I., \& Greenberg, G. Z. (1959). Operating characteristics determined by binary decisions and by ratings. Journal of the Acoustical Society of America, 31, 768-773. 
Running Head: WORKING MEMORY AND CONFIDENCE PROCESSING

Engle, R. W., Kane, M. J., \& Tuholski, S. W. (1999). Individual differences in working memory capacity and what they tell us about controlled attention, general fluid intelligence and functions of the prefrontal cortex. In A. Miyake \& P. Shah (Eds.), Models of working memory: Mechanisms of active maintenance and executive control (pp. 102-134). New York: Cambridge University Press.

Ferrel, W. R., \& McGoey, P. J. (1980). A model of calibration for subjective probabilities. Organizational Behaviour and Human Performance, 26, 32-53.

Gigerenzer, G., Hoffrage, U., \& Kleinbölting, H. (1991). Probabilistic mental models: A Brunswikian theory of confidence. Psychological Review, 98, 506-528.

Hasher, L., \& Zacks, R. T. (1979). Automatic and effortful processes in memory. Journal of Experimental Psychology: General, 108, 356-388.

Henmon, V. A. C. (1911). The relation of the time of a judgment to its accuracy. Psychological Review, 18, 186-201.

Hochman, E. Y. \& Evitar, Z. (2004). Does each hemisphere monitor the ongoing process in the contralateral one? Brain and Cognition, 55, 314-321.

Hochman, E. Y. \& Meiran, N. (2005). Central interference in error processing. Memory \& Cognition, 33, 635-643.

James, W. (1890/1950). The Principles of Psychology, Vol. 1. New York: Dover..

Jolicoeur, P. (1999). Restricted attentional capacity between sensory modalities. Psychonomic Bulletin \& Review, 6, 87-92. 
Running Head: WORKING MEMORY AND CONFIDENCE PROCESSING

Juslin, P., \& Olsson, H. (1997). Thurstonian and Brunswikian origins of uncertainty in judgement: A sampling model of confidence in sensory discrimination. Psychological Review, 104, 344-366.

Kareev, Y. (1992). Not that bad after all: Generation of random sequences. Journal of Experimental Psychology: Human Perception and Performance, 18, 1189-1194.

Keren, G. (1991). Calibration and probability judgments: Conceptual and methodological issues. Acta Psychologica, 77, 217-273.

Laming, D. R. (1968). Information theory of choice reaction time. New York: Wiley.

Lichtenstein, S., Fischhoff, B., \& Phillips, S. D. (1982). Calibration of probabilities: The state of the art to 1980. In D. Kahneman, P. Slovic, \& A. Tversky (Eds.), Judgment under uncertainty: Heuristics and biases (pp. 306-344).

CambridgeUniversity Press.

Link, S. W. \& Heath, R. A. (1975). A sequential theory of psychological discrimination. Psychometrika, 40, 77-105.

Logan, G. D. (1988). Toward an instance theory of automatization. Psychological Review, 95, 492-527.

Logie, R. H. (1995). Visuo-spatial working memory. Hove: Lawrence Erlbaum Associates, Ltd.

Lovett, M. C., Reder, L. M., \& Lebière, C. (1999). Modelling working memory in a unified architecture: an ACT-R Perspective. In A. Miyake \& P. Shah (Eds.), Models of working memory: Mechanisms of active maintenance and executive 
Running Head: WORKING MEMORY AND CONFIDENCE PROCESSING control (pp. 28-61). Cambridge, England: Cambridge University Press.

McCann, R. S., \& Johnston, J. C. (1992). Locus of single-channel bottleneck in dual-task interference. Journal of Experimental Psychology: Human Perception \& Performance, 18, 471-484.

McElree, B. (2001). Working Memory and Focal Attention. Journal of Experimental Psychology: Learning, Memory, and Cognition, 27, 817-835.

Miller, G. A. (1956/1994). The magical number seven, plus or minus two: Some limits on our capacity for processing information. Psychological Review, 63, 81-97.

Miyake, A. \& Shah, P. (1999). Toward unified theories of working memory: Emerging general consensus, unresolved theoretical issues and future directions. In A. Miyake \& P. Shah (Eds.). Models of working memory: Mechanisms of active maintenance and executive control (pp. 28-61). Cambridge, England: Cambridge University Press.

Neuringer, A. (1986). Can people behave "randomly"? The role of feedback. Journal of Experimental Psychology: General, 115, 62-75.

Nickerson, R. S. (2002). The production and perception of randomness. Psychological Review, 109, 330-357.

Norman, D. A. (1968). Toward a theory of memory and attention. Psychological Review, $75,522-536$.

Norman, D. A., \& Shallice, T. (1980). Attention to action. Willed and automatic control of behavior. University of California San Diego CHIP Report 99. 
Running Head: WORKING MEMORY AND CONFIDENCE PROCESSING

Norman, D. A., \& Shallice, T. (1986). Attention to action: Willed and automatic control of behaviour. In R. J. Davidson, G. E. Schwarts, \& D. Shapiro (Eds.), Consciousness and self-regulation: Advances in research and theory (Vol. 4, pp. 1-18). New York: Plenum

Oberauer, K. (2002). Access to information in working memory: Exploring the focus of attention. Journal of Experimental Psychology: Learning, Memory, and Cognition, 28, 411-421.

Pierce, C. S., \& Jastrow, J. (1884). On small differences in sensation. Proceedings of the National Academy of Sciences, 3, 75-83.

Peterson, L. R., \& Peterson, M. J. (1959). Short term retention of individual verbal items. Journal or Experimental Psychology, 58, 193-198.

Petrusic, W. M. (1992). Semantic congruity effects and theories of the comparison process. Journal of Experimental Psychology: Human Perception and Performance, 18, 962-986.

Petrusic, W. M., \& Baranski, J. V. (1997). Context, feedback, and the calibration and resolution of confidence in perceptual judgments. American Journal of Psychology, 110, 543-572.

Petrusic, W. M., \& Baranski, J. V. (2003). Judging confidence influences decision processing in comparative judgments. Psychonomic Bulletin and Review, 10, 177 183.

Petrusic, W. M., \& Baranski, J. V. (2000). Effects of expressing confidence on decision 
Running Head: WORKING MEMORY AND CONFIDENCE PROCESSING

processing: Implications for theories of RT and confidence. In C. Bonnett (Ed.)

Fechner Day 2000: Proceedings of the Sixteenth Annual Meeting of the

International Society for Psychophysics (pp. 103-108). Strasbourg, France: The

International Society for Psychophysics.

Posner, M. I., \& Snyder, C. R. R.(1974). Attention \& cognitive control. In R. Solso (Ed.), Information Processing and Cognition: The Loyola Symposium (pp. 55-85).

Hillsdale, NJ: Erlbaum.

Repovs, G., \& Baddeley, A. D. (2006) Multi-component model of working memory: Explorations in experimental cognitive psychology. Neuroscience Special Issue, $139,5-21$

Rogers, R. D., \& Monsell, S. (1995). Costs of a predictable switch between simple cognitive tasks. Journal of Experimental Psychology: General, 124, 207-231.

Schneider, W., \& Shiffrin, R. M. (1977). Controlled and automatic human information processing: I. Detection, search, and attention. Psychological Review. 84, 1-66.

Schoenherr, J. R., Leth-Steensen, C., \& Petrusic, W. M. (2005). Attentional allocation and subjective confidence calibration. In Monahan, J. S., Sheffert, S. M. \& Townsend, J. T., (Ed.) Fechner Day 2005: Proceedings of the $21^{\text {st }}$ Annual Meeting of the International Society for Psychophysics (pp. 103-108). Traverse City, USA: The International Society for Psychophysics.

Schoenherr, J. R., Leth-Steensen, C., \& Petrusic, W. M. (2006). Selective attention and confidence processing. . In Kornbrot, D., Msetfi, R., MacRae, S. (Ed.) Fechner 
Day 2000: Proceedings of the $22^{\text {nd }}$ Annual Meeting of the International Society for Psychophysics (pp. 103-108). Hertfordshire, England: The International Society for Psychophysics.

Shallice, T. (1982). Specific impairments of planning. Philosophical Transactions of the Royal Society London B 298, 199-209.

Shiffrin, R. M., \& Schneider, W. (1977). Controlled and automatic human information processing: II. Perceptual learning, automatic attending, and a general theory. Psychological Review, 84, 127-190.

Smilek, D., Eastwood, J. D., \& Merikle, P. M. (2000). Does unattended information facilitate change detection? Journal of Experimental Psychology: Human Perception and Performance, 26(2), 480-487.

Sumner, F. B. (1898). A statistical study of belief. Psychological Review, 5, 616-631.

Szmalec, A., Vandeirendonck, A., \& Kemps, E. (2005). Response selection involves executive control: Evidence from the selective interference paradigm. Memory \& Cognition, 33, 531-541.

Tune, G. S. (1964). A brief survey of variables that influence random generation. Perceptual and Motor Skills, 18, 705-710.

Vickers, D., 1970. Evidence for an accumulator model of psychophysical discrimination. In: A.T. Welford \& L. Houssiadas (eds.). Current problems in perception; Ergonomics, 13, 37-58.

Vickers, D. (1979). Decision processes in visual perception. New York: Academic Press. 
Wagnenaar, W. A. (1972). Generation of random sequences by human subjects: A critical survey of literature. Psychological Bulletin, 77, 65-72. 
Appendix

\section{A1.0 Analysis of Randomization Task}

In the current study, randomization performance was measured with three metrics: redundancy, alternations, and adjacency (for reviews of these and other indices of randomness see Ginsburg \& Karpiuk, 1994; Towse \& Neil, 1998). The rationale for using each of these measures is discussed below.

\section{A1.1 Redundancy}

The measure of redundancy $(R)$ is based on the assumption that a random sequence should have each response alternative represented with equal frequency and is therefore said to contain a maximum amount of first-order information (Towse \& Neil, 1998). The amount of first-order information in a particular sequence is given by the formula:

$$
H_{\text {single }}=\log 2 n-1 / n\left(\Sigma \log 2 n_{\mathrm{i}}\right)
$$

where $n$ is the total number of responses in a sequence, and $n_{\mathrm{i}}$ is the number of instances where the $i$ th response alternative is used. When a response alternative does not appear in a sequence (i.e., $n_{\mathrm{i}}=0$ ) it is excluded from the analysis. The maximum amount of firstorder information permitted with a set of $y$ alternatives is given by the formula:

$$
H_{\text {max }}=\log _{2} y
$$

To determine the extent to which a sequence deviates from the equiprobability assumption, a redundancy $(R)$ score is obtained with the formula:

$$
R=100 \times\left(1-H_{\text {single }} / H_{\max }\right)
$$


Thus, small values of $R$ indicate sequences where the response alternatives are represented with equal frequency, whereas large values of $R$ indicate sequences with greater repetition of a subset of the response alternatives.

\section{A1.2 Alternation}

Another index of randomness measures a participant's alternation between response alternatives. A persistent finding of randomization studies is that participants generally exhibit negative recency, or a tendency to avoid repetition of the last response alternatives (for a review see Wagnenaar, 1972). To examine patterns of repetition and alternation, we must identify the percentage of non-identical pairs (i.e., AE, FA, etc.) in a given sequence. An index of alternations $\left(A_{\mathrm{p}}\right)$ is given by the formula:

$$
A p=100 \times\left(n_{\mathrm{i}}\right) /(n)
$$

where $n$ is the total number of response pairs, and $n_{\mathrm{i}}$ is the number of instance where the $i$ th set of non-identical pairs that are present in a sequence. High values of $A_{p}$ indicate that a participant tends to alternate between responses alternatives, whereas low values of indicate a tendency to repeat the same response.

\section{A1.3 Adjacency}

In addition to identifying alternations in response, we can also consider pairs that are adjacent to one another in the ordinal sequence of the response alternatives (e.g., $\mathrm{AB}$, $\mathrm{CD}, \mathrm{EF})$. The index of adjacency $(A)$ examines the number of adjacent pairs present in a random sequence. Adjacency is given by the same formula as $A_{\mathrm{p}}$ except that $n_{\mathrm{i}}$ represents the number of instances where the $i$ th set of adjacent pairs are used by the participant. 


\section{A2.0 Results}

The dependent variables used in the present analyses were the measures of redundancy, alternations, and adjacency. The indices of randomness were analyzed in separate ANOVAs that included the three working memory load conditions (decision load, full load, and randomization only) as the within-subjects factor and instructional emphasis (speed and accuracy stress) as the between-subject factor. No posthoc analyses were performed.

\section{A2.1 Redundancy}

In the ANOVA with redundancy as the dependent measure, the mean frequency with which participants used a given response alternative was found to be significantly affected by the load condition, $F(2,56)=9.219, p<.001, M S E=1.006$. The means in Table 1A, and also below, indicate that participants were in fact producing more random responses under the full load condition, slightly fewer random responses in the randomization only condition, and the fewest random responses in the decision load condition. If we consider the pattern evident in both DRT and CRT along with the present findings, we can conclude that when participants perform confidence processing concurrently with the randomization task their randomization performance increases. Lastly, the main effect of the speed and accuracy stress narrowly missed significance, $F(1,28)=4.015, p=.055$. As Table $1 \mathrm{~A}$ indicates, when participants were required to render rapid primary decision responses they produced fewer random responses then when they were required to respond as accurately as possible to the primary decision. 
Running Head: WORKING MEMORY AND CONFIDENCE PROCESSING

Table A1. Percentage Redundancy for Each Working Memory Load Condition Under Both Speed and Accuracy Emphasis.

\section{Decision Load Full Load Randomization Only Mean}

$\begin{array}{lllll}\text { Accuracy } & 6.951 & 5.939 & 6.225 & 6.372 \\ \text { Speed } & 8.738 & 7.728 & 7.649 & 8.038 \\ \text { Mean } & 7.845 & 6.834 & 6.937 & 7.205\end{array}$

\section{A2.2 Alternations}

The index of alternations was significantly affected by working memory load, $F(2$, $56)=4.278, p<.05, M S E=.596$. The means in Table A2 indicate that participants were less likely to alternate between letter responses when in the full load condition than when they were required to randomize letters alone or had to randomize letters while making a primary decision. As with the redundancy results, the results of alternation analysis support the conclusion that when confidence processing is performed with a concurrent randomization load, a participant's ability to randomize letters improves. 
Table A2. Percentage Alternations for Each Working Memory Load Condition Under Both Speed and Accuracy Emphasis.

Decision Load Full Load Randomization Only Mean

$\begin{array}{lllll}\text { Accuracy } & 99.229 & 98.644 & 98.960 & 98.951 \\ \text { Speed } & 98.720 & 98.177 & 98.669 & 98.522 \\ \text { Mean } & 98.975 & 98.411 & 98.815 & 98.737\end{array}$

\section{A2.3 Adjacency}

Unlike redundancy and alternations, working memory load did not have a significant effect on the number of adjacent pairs used, $F(2,56)=.915, p=.40$. As the means in Table A3 indicate, participants had an overall tendency to use adjacent pairs and did so $40 \%$ of the time. This result confirms the general difficulty participants had in avoiding stereotypic responding in the production of random letter sequences (Baddeley, 1966).

Table A3. Percentage Adjacent Pairs for Each Working Memory Load Condition Under Both Speed and Accuracy Emphasis.

Decision Load Full Load Randomization Only Mean

$\begin{array}{lllll}\text { Accuracy } & 40.538 & 41.023 & 39.952 & 40.504 \\ \text { Speed } & 39.757 & 40.066 & 38.744 & 39.522 \\ \text { Mean } & 40.148 & 40.545 & 39.348 & 40.013\end{array}$




\section{A3.0 Discussion}

The present results indicate that participants display more randomness in their responses when they have a randomization task that is performed over both the decision and confidence processes (i.e., the full load condition), marginally less random responses when they randomize letters without a secondary task (i.e., the randomization only condition), and the most non-random responses when they are required to randomize concurrently with a secondary task (i.e., the decision load condition). Taken together with the observed increases in DRT in the full load condition and CRT in the decision load condition, these results indicate that when confidence processing is performed concurrently with the primary decision, performance gains are observed in random responses.

Two explanations for the present findings are possible depending on the role that is assigned to memory in random production (cf. Tune, 1964; Baddeley 1966). The first explanation requires that the items retained in memory interfere with random production (Baddeley, 1966). If this is the case, then using these resources to process confidence reduces the number of previous responses that are stored in memory that would otherwise interfere with random production. Similarly, if confidence processing is postponed when a load is placed on decision, it would result in the fewest number of random responses as central executive resources are freely available during the primary decision.

An alternative explanation is that computing confidence concurrently with the primary decision results in improvement in the randomization task due to additional 
monitoring of random response production. In this case, by shifting the locus of confidence processing into the primary decision, any concurrent processes would benefit from the monitoring of performance. However, this interpretation imputes a great deal to the performance enhancing effects of concurrent confidence processing; more so than is warranted given that these gains have only been observed in rare instances (e.g., cf., Baranski and Petrusic, 2003; Schoenherr et al., 2005, 2006).

The above considerations notwithstanding, we can conclude that the pattern observed here complements those observed in the analyses of the other dependent measures (i.e., accuracy, DRT, and CRT). Although we must readily acknowledge that there may be a trade-off between the primary decision, confidence processing, and random sequence production that is unaccounted for, the randomization analysis conforms to the pattern of performance we would expect if confidence processing occurred during the primary decision under full load but is postponed to a postdecisional locus when the load occurs only during the primary decision. Along with the other findings presented above, these results support an alterable locus for confidence processing that is dependent on the central executive resources of working memory. 